Article

\title{
Control Structures Evaluation for a Salt Extractive Distillation Pilot Plant: Application to Bio-Ethanol Dehydration
}

\author{
Carlos Alberto Torres Cantero, Guadalupe Lopez Lopez * (D), Victor M. Alvarado, \\ Ricardo F. Escobar Jimenez, Jesse Y. Rumbo Morales and Eduardo M. Sanchez Coronado \\ Tecnológico Nacional de México, TecNM/CENIDET, Int. Interado Palmira S/N, Col. Palmira, Cuernavaca \\ 62490, Mexico; atorres@itcolima.edu.mx (C.A.T.C.); alvarado@cenidet.edu.mx (V.M.A.); esjiri@cenidet.edu.mx \\ (R.F.E.J.); jjrumbo@hotmail.com (J.Y.R.M.); edusanchez@cenidet.edu.mx (E.M.S.C.) \\ * Correspondence: guadalupe@cenidet.edu.mx; Tel.: +52-777-362-7770 (ext. 2213) \\ Academic Editor: Talal Yusaf \\ Received: 21 July 2017; Accepted: 25 August 2017; Published: 27 August 2017
}

\begin{abstract}
This paper addresses the challenge of evaluating control structures for a salt extractive distillation column producing absolute ethanol for use as biofuel. A sensitivity analysis aided with designing a pseudo-binary distillation pilot plant and examining the conceived process and the influence of the reflux ratio on both product purity and energy consumption. We compare three control structures for inferential tracking of the distillate composition: a dual-temperature control with an RV (reflux/boilup) structure and two single-end temperature control configurations, and their performance is measured using deterministic indicators. The result is the proposal of a pilot plant design for treating $15 \mathrm{~kg} / \mathrm{h}$ of a diluted mixture with mole fraction of ethanol equal to 0.2 and assuming a column efficiency of $50 \%$. The $\mathrm{R} / \mathrm{F}$ (reflux to feed ratio) configuration is the best control structure, given that its corresponding performance indicators conduct lowest steady-state errors, less oscillating responses, and reduced settling times. For this configuration, the reflux flow rate is rationed to the feed flow rate, and the temperature is controlled manipulating the distillate flow rate. Even subject to perturbations, the energy consumption of the plant remains close to the nominal value. The three evaluated control structures consistently met international quality standards for fuel ethanol and enhanced the use of salts in ethanol dehydration.
\end{abstract}

Keywords: absolute ethanol; bio-fuel; salt extractive distillation; distillation control

\section{Introduction}

The bioethanol used as biofuel derives from the fermentation of agricultural feedstocks. The type of biomass consumed determines the production technology. At present, it is predominantly a first-generation fuel, i.e., produced through established fermentation technologies from sugar or starch, essentially from corn and sugar cane. However, there is a growing interest in second-generation ethanol, i.e., produced through more sustainable technologies from lignocellulosic materials such as energy crops, aquatic plants, forests biomass, agricultural residues, municipal and industrial solid wastes [1-3]. Conventional fermentation processes yield ethanol-water diluted mixtures of $8 \%$ to $10 \%$ mole of ethanol [4], but improved technologies result in higher conversion, producing mixtures of $15 \%$ mole of ethanol [5].

Subsequent purification of the fermentation broth by binary distillation yields ethanol with maximum purity close to $90 \%$ mole, which is insufficient for substituting gasoline or additive of gasoline in vehicles; anhydrous ethanol is necessary to promote these applications. The difficulty to produce anhydrous ethanol by ordinary binary distillation lies in the thermodynamic behavior 
of the ethanol-water system since it forms an azeotrope at $90.37 \%$ mole of ethanol, pressure of $1.01325 \mathrm{bar}$ and temperature of $78.17^{\circ} \mathrm{C}$ [6]. The technologies for obtaining absolute ethanol include a diversity of distillation processes conceived to modify the non-ideal thermodynamic behavior of the ethanol-water system, such as homogeneous and heterogeneous azeotropic distillation, vacuum distillation, extractive distillation with solvents, with soluble salts or with ionic liquids, diffusion distillation and reactive distillation. Other separation technologies are chemical dehydration processes, adsorption, membrane processes including reverse osmosis, pervaporation and gas or vapor permeation, and, finally, hybrid processes [7-9].

The azeotropic distillation, the extractive distillation with solvent and the adsorption have been the preferred technologies at the industrial scale to dehydrate ethanol, but, at this time, attempts are focused on replacing organic solvents in industry, and the idea is to prevent the handling of toxic separating agents that additionally implicate subsequent recovery processes. In this sense, salts and ionic liquids are green alternative separating agents with favorable azeotrope breaking capacity for producing absolute ethanol.

Ionic liquids (ILs) represent a promising alternative to ethanol dehydration as they combine easy handling (of liquid organic solvents) and a high capability of azeotropic point breaking (of solid salts); additionally, their negligible vapor pressure facilitates their recovery by stripping, evaporation, drying or crystallization [10-14]. At the actual state of development of the IL technology, process simulators such as Aspen Plus need user-defined properties to treat ILs as pseudo-components in extractive distillation simulations, and current research includes process modeling promoted at laboratory scale or in simulation, but their performance in larger scale production is relatively unknown. Quijada-Maldonado et al. [15] proposed a rate based model validated with pilot-plant experiments, they suggested that the characteristic high viscosity of ILs can affect the distillation efficiency, then a rate based model should estimate the effect of the entrainer viscosity by using correct models of physical and transport properties and should improve the prediction of the steady-state behavior. More recently, Ramírez-Corona [16] proposed tray-by-tray calculations and used data reported in the literature and the non-random two-liquid (NRTL) model for non-electrolytes to estimate the vapor-liquid equilibrium (VLE) of the system. In a later work, Zhu et al. [10] proposed a sensitivity analysis for minimum energy consumption, based on Aspen Plus simulations. Results demonstrate that a wide range of ILs have the potential for being integrated at the industrial-scale in ethanol dehydration processes and are easier to handle than solid salts, but some authors emphasize the need for selecting ILs with low viscosity.

On the other hand, it is well-known that the use of salts was abandoned in the industry in 1965 due to operational difficulties caused by poor dissolution and subsequent recrystallization of salts, which in turn contributed to corrosion problems. At that time, the limited solubility data and the need for complex thermodynamic equilibrium models were also factors restraining the application of the salt extractive distillation. However, the effectiveness of this process to produce absolute ethanol and its operating advantages are evident at the industrial scale given that more than 100 plants based on the Holz Industrie Actien Geselleschaft (HIAG) process were established in Europe between 1930 and 1950 [17]. The advantages of this technology were also confirmed by the development of processes for different scales that include packed columns or tray columns [17-22]. Additionally, the various studies on salt extractive distillation have overcome some drawbacks throughout the time due to the development of theoretical, experimental and modeling advances relating to the salting-out effect. The actual environmental and energy policies promote saving of energy and give rise to a renewed interest for salt extractive distillation, which compared with other dehydration processes have the benefits of energy saving, reduced equipment size and initial costs, high purity products obtained with a single column and the feasibility of production at different scales.

Particularly, calcium chloride $\left(\mathrm{CaCl}_{2}\right)$ has been widely used as a separating agent in salt extractive distillation because this electrolyte effectively modifies the phase equilibrium of the ethanol-water system, experimental data of phase equilibrium is reported for this system [23], and the performance of 
the ethanol dehydration has been evaluated for experimental processes at different scales $[17,19,24,25]$ and with the aid of steady-state numerical simulations [20,26,27].

In contrast, classic processes such as azeotropic distillation and adsorption need a preconcentration distillation column and a recovery process since the feed current must enter close to the azeotropic point and the separating agent is recycled. These requirements increase the plant size, the initial investment, and the production costs. Concerning the more advanced technologies, these need expensive materials, and high initial and maintenance costs. Moreover, the industrial implementation is not highly developed. However, these new technologies have a great potential to be developed at the industrial scale in the short- or medium-term to produce absolute ethanol.

One aspect that cannot fail in order to improve the performance of real industrial processes is the incorporation of adequate control strategies. Fundamentals on two-products distillation control have been extensively revised, some indispensable reference works are those of [28-42]. The classical approach to control multi-variable distillation processes is to treat a decoupled control system, and different configurations can be useful in different scenarios to address interaction between variables and between control loops. Nevertheless, the choice of the control structure certainly represents a deal as the nonlinear nature of the various distillation systems can produce complex and varied behaviors. Studies on control for ethanol dehydration applications concentrates the processes most widely used in the industry. In this way, the control of azeotropic distillation columns is basically associated with multiple steady-states, and involves liquid-liquid equilibrium that imposes distillation boundaries limiting the operating range as well as the control of multiple-distillation columns with recycles [43]. The control of extractive distillation columns entails less difficulties and is the most frequently discussed in the literature [44-49]. The control of salt extractive distillation is still not an open research topic.

A common agreement is that understanding the steady-state behavior of distillation columns is the basis for designing suited strategies of processes control. In this work, we provide some insights on examining the effectiveness of different control structures for inferential tracking of the distillate composition in a pseudo-binary distillation column. We consider the design of a salt extractive distillation pilot plant for absolute ethanol production with a special emphasis on establishing a balance between analysis of the steady-state behavior and the selection and evaluation of the closed-loop strategy. In addition, we discuss the results on the basis of a quantitative evaluation with deterministic indicators. The paper is organized as follows: Section 2 is dedicated to presenting the salt extractive distillation process, which includes explaining the methodology of simulation, as well as providing the vapor-liquid equilibrium (VLE) prediction and a sensitivity analysis useful to size the column at a pilot plant level. In Section 3, we describe selected control structures with dual and single temperature tracking to inferentially regulate the distillate composition. In Section 4, we discuss the results of a comparative analysis of the proposed control structures. The evaluation is made based on measurement of integral-errors and classical performance indicators of the closed-loop response of the process, then the interpretation aids to identify the most effective control structure and to verify some issues in accordance with the steady-state analysis outcomes. Finally, concluding remarks in Section 5 offer a synthesis of the procedures, objectives and significance of the work.

\section{Salt Extractive Distillation Process}

\subsection{Simulation Methodology}

The simulator of the salt extractive distillation column for dehydrating fuel ethanol was built within the Aspen Plus ${ }^{\circledR} /$ Aspen Dynamics ${ }^{\circledR}$ (aspenONE ${ }^{\circledR}$ v8, Aspen Technology, Inc. Burlington, MA USA) environment. We used the RADFRAC module for simulating the steady-state performance. The module solves the so-called MESH equations for modeling equilibrium stages, which includes Mass Balance Equations (M), Equilibrium Relations (E), Sum or Conservation Equations (S) and Heat 
or Enthalpy Balance Equations $(\mathrm{H})$. The simulation was performed in terms of the apparent mole fractions defined for the electrolytic system (6) in Section 2.2.

Aspen Plus has Symmetric and Unsymmetric Electrolyte NRTL Activity Coefficient Models. The ENRTL-RK (electrolyte NRTL - Redlich-Kwong) was used to determine the VLE behavior of the ethanol-water- $\mathrm{CaCl}_{2}$ system, and it is based on the Unsymmetric Electrolyte NRTL activity coefficient model (GMENRTLQ) with unsymmetric reference states for ions at infinite dilution in aqueous solution, but they differ slightly in the mixing rules used for multiple electrolytes, which is not the case for the considered mixture.

The parameters of the former NRTL model for computing the liquid activity coefficients of the binary ethanol-water system were obtained from the Aspen Plus VLE-IG (VLE ideal gas) database and are reported in Table 1 in the columns of binary interactions. The adjustable parameters needed to predict the ethanol-water- $\mathrm{CaCl}_{2}$ VLE (with the ENRTL-RK model) are the symmetric non-random factor parameters $\alpha$ and the asymmetric binary interaction energy parameters $\tau$, which were estimated for different type of interactions to complete the database. The model parameters for molecule-molecule pair interactions $\left(\alpha_{m m^{\prime}}=\alpha_{m^{\prime} m}\right.$ and $\left.\tau_{m m^{\prime}} \neq \tau_{m^{\prime} m}\right)$ were estimated by using Equation (1) in terms of $a_{i j}, b_{i j}, c_{i j}$ and making the temperature (T) dependent parameters $d_{i j}, e_{i j}, f_{i j}$ equal to zero, and the resulting values are provided in Table 1 , referred to as molecule-molecule pairs. Furthermore, the molecule-electrolyte pair interactions $\left(\alpha_{m, c a}=\alpha_{c a, m}\right.$ and $\left.\tau_{m, c a} \neq \tau_{c a, m}\right)$ were estimated by means of the Data Regression System (DRS) of Aspen Properties and are reported as molecule-electrolyte pairs in Table 1. Finally, the electrolyte-electrolyte interaction pairs $\left(\alpha_{c a, c a^{\prime}}=\alpha_{c a^{\prime}, c a}\right.$ and $\alpha_{c a, c^{\prime} a}=\alpha_{c^{\prime} a, c a}$; $\tau_{c a, c a^{\prime}} \neq \tau_{c a^{\prime}, c a}$ and $\tau_{c a, c^{\prime} a} \neq \tau_{c^{\prime} a, c a}$ ) were considered equal to zero:

$$
\begin{aligned}
\tau_{m_{1}, m_{2}} & =a_{m_{1}, m_{2}}+\frac{b_{m_{1} m_{2}}}{T}+e_{m_{1}, m_{2}} \ln T+f_{m_{1}, m_{2}} T, \\
\alpha_{m_{1}, m_{2}} & =c_{m_{1}, m_{2}}+d_{m_{1}, m_{2}}(T-273.15 K) .
\end{aligned}
$$

Table 1. Interaction parameters for ethanol-water system obtained from the Data Bank VLE-IG of Aspen Plus and interaction parameters for ethanol-water- $\mathrm{CaCl}_{2}$ system obtained by VLE data

\begin{tabular}{|c|c|c|c|c|c|}
\hline \multirow{2}{*}{\multicolumn{2}{|c|}{$\begin{array}{c}\text { Ethanol-Water (NRTL) } \\
\text { Binary Interactions } \\
\end{array}$}} & \multicolumn{4}{|c|}{ Ethanol-Water-CaCl ${ }_{2}$ (ENRTL) } \\
\hline & & \multicolumn{2}{|c|}{ Molecule-Molecule Pairs } & \multicolumn{2}{|c|}{ Molecule-Electrolyte Pairs } \\
\hline $\mathbf{i}$ & $\begin{array}{l}\text { Ethanol } \\
\text { Water }\end{array}$ & $\begin{array}{l}\mathbf{m}_{1} \\
\mathbf{m}_{2}\end{array}$ & $\begin{array}{l}\text { Ethanol } \\
\text { Water }\end{array}$ & $\begin{array}{c}\mathbf{m}_{1} \\
\mathbf{m}_{2} \\
\mathbf{c a}\end{array}$ & $\begin{array}{c}\text { Ethanol } \\
\text { Water } \\
\mathrm{CaCl}_{2}\end{array}$ \\
\hline $\begin{array}{l}\mathrm{a}_{i j} \\
\mathrm{a}_{j i} \\
\mathrm{~b}_{i j} \\
\mathrm{~b}_{j i} \\
\mathrm{c}_{i j}\end{array}$ & $\begin{array}{c}-0.8009 \\
3.4578 \\
246.18 \\
-586.0809 \\
0.3\end{array}$ & $\begin{array}{l}\tau_{m_{1}, m_{2}} \\
\tau_{m_{2}, m_{1}} \\
\alpha_{m_{1}, m_{2}}\end{array}$ & $\begin{array}{c}-0.141166 \\
1.8872 \\
0.3\end{array}$ & $\begin{array}{l}\tau_{m_{1}, c a} \\
\tau_{c a, m_{1}} \\
\alpha_{m_{1}, c a} \\
\tau_{m_{2}, c a} \\
\tau_{c a, m_{2}} \\
\alpha_{m_{2}, c a}\end{array}$ & $\begin{array}{c}50.7409314 \\
-25.439654 \\
0.0293 \\
11.6224635 \\
-5.8749949 \\
0.2\end{array}$ \\
\hline
\end{tabular}
regression.

The VLE model of the ethanol-water- $\mathrm{CaCl}_{2}$ was correlated on salt-free basis mole fractions, defining a pseudo-binary mixture (7) as indicated in Section 2.2, Later on, the VLE prediction was validated with experimental data; the fitting results and the estimated interaction parameters are presented in Section 2.2. With the goal to demonstrate the validity of the salt extractive distillation simulator, we considered the process design used by Llano-Restrepo et al. [26] and Hashemi et al. [27], and we compared their steady-state modeling solution with the results of our plant simulator built within the Aspen-Plus environment. The temperature and compositions profiles obtained by the Aspen-Plus simulator match the profiles provided by the two reference works (Figures 1 and 2). 
On the basis of a reliable steady-state simulator, we designed an ethanol dehydration pilot plant, and we present its operating configuration in Section 2.3. As part of a flow-driven dynamic simulation carried-out in Aspen-Dynamics, following on from this design, we decided to prove three control structures (which are described in Section 3); then, we evaluated and compared their performances by means of different criteria (in Section 4). Here, we define the deterministic indicators: Integral time-weighted absolute error (ITAE), measuring persistent errors, Equation (4), Integral absolute error (IAE), Equation (3) and integral squared error (ISE), measuring large errors, Equation (2) that we used in addition to other classic performance indicators:

$$
\begin{gathered}
\text { ISE }=\int_{0}^{\infty} e(t)^{2} d t, \\
\text { IAE }=\int_{0}^{\infty}|e(t)| d t, \\
\text { ITAE }=\int_{0}^{\infty} t|e(t)| d t
\end{gathered}
$$

where the signal error $e(t)$ is the difference between the set-point or steady-state and the analyzed measured signal over time $(t)$.

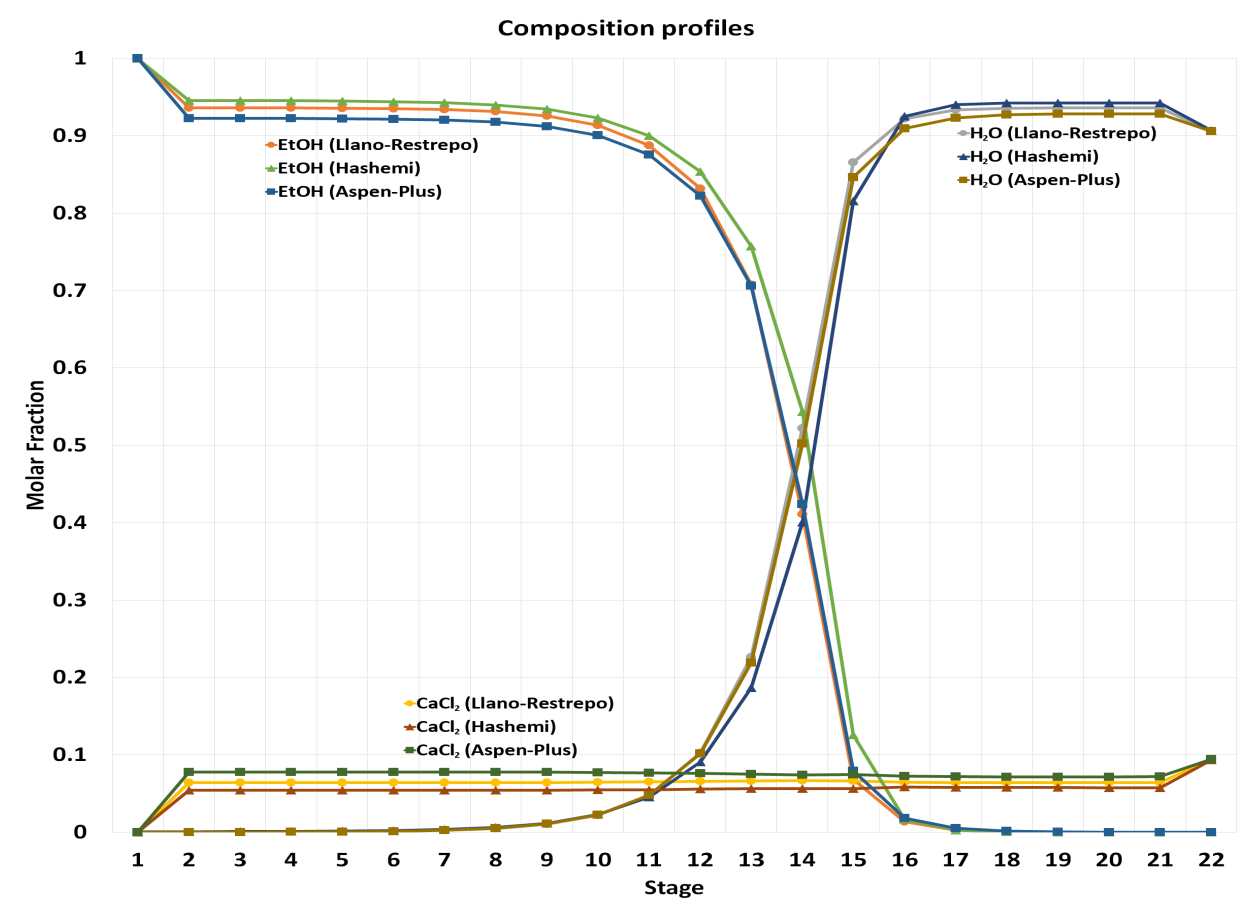

Figure 1. Composition profiles of the salt extractive distillation column. Comparison between Llano-Restrepo et al. [26] and Hashemi et al. [27]. 


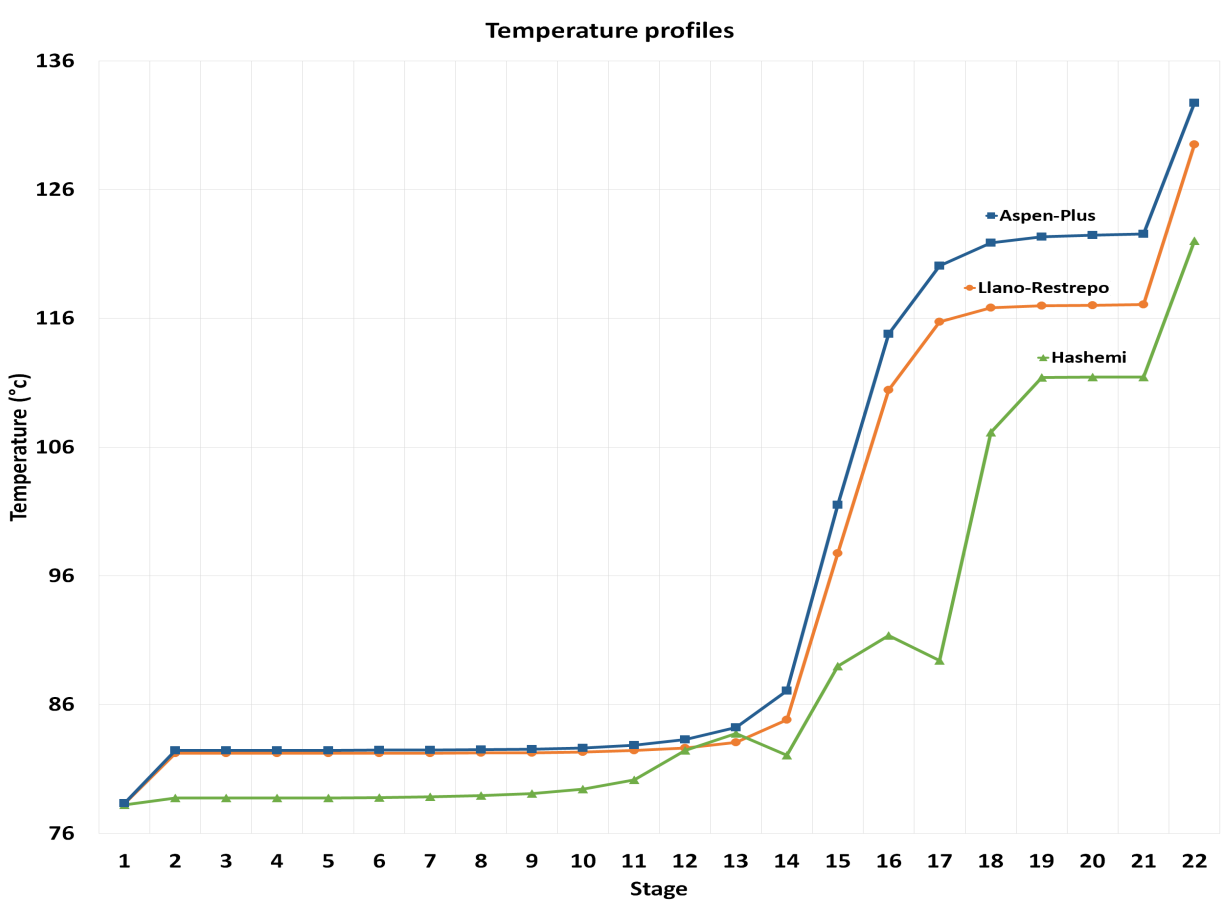

Figure 2. Temperature profiles of the salt extractive distillation column. Comparison between Llano-Restrepo et al. [26] and Hashemi et al. [27].

\subsection{Vapor-Liquid Equilibrium Prediction}

The reliability of the distillation simulation depends on the validity of the phase equilibrium prediction, which is a demanding task owing to the non-ideal and electrolytic nature of the system. The Calcium Chloride $\left(\mathrm{CaCl}_{2}\right)$ is an effective separating agent in extractive distillation of mixtures composed of ethanol and water, and this electrolyte has an experimentally proved salting-out effect on the ethanol-water VLE. When a small quantity of $\mathrm{CaCl}_{2}$ is added to the binary mixture, the salt is dissociated in solution by the water at the same time that the relative volatility of ethanol increases to such an extent that the ethanol-water azeotrope is broken.

The VLE data of the ethanol-water- $\mathrm{CaCl}_{2}$ system must be consistently expressed either, in terms of [26]:

- The true mole fractions $x_{t r, i}$ with $i=1, \cdots, 4$. Equation (5) defining the composition of the quaternary system: ethanol[1]-water[2]-Ca ${ }^{+2}[3]-\mathrm{Cl}^{-1}[4]$ :

$$
\begin{aligned}
& x_{t r, 1}=\frac{x_{1}}{2 x_{3}+1}, \\
& x_{t r, 2}=\frac{x_{2}}{2 x_{3}+1}, \\
& x_{t r, 3}=\frac{x_{3}}{2 x_{3}+1}, \\
& x_{t r, 4}=\frac{2 x_{3}}{2 x_{3}+1} .
\end{aligned}
$$

- The apparent mole fractions or stoichiometric fractions $x_{i}$ with $i=1, \cdots, 3$. Equation (6) defining the composition of the ternary system: ethanol[1]-water[2]- $\mathrm{CaCl}_{2}[3]$ :

$$
\begin{aligned}
& x_{1}=x_{s f, 1}\left(1-x_{3}\right), \\
& x_{2}=x_{s f, 2}\left(1-x_{3}\right), \\
& x_{3}=\frac{x_{s f, 3}}{1+x_{s f, 3}}
\end{aligned}
$$


- Or, on a salt-free basis mole fractions defining a pseudo-binary mixture: ethanol $/ \mathrm{CaCl}_{2}[1]$-water $/ \mathrm{CaCl}_{2}[2]$. Herein, $x_{s f, i}$ with $i=1,2$ are the liquid phase salt-free mole fraction corresponding to the vapor phase mole fraction of ethanol $y_{s f, 1}$ and the vapor phase mole fraction of water $y_{s f, 2}$. The salt concentration is calculated as indicated in Equation (7):

$$
\begin{aligned}
x_{s f, 3} & =0.167 \frac{M_{w}}{M_{w, 3}}, \\
M_{w} & =x_{s f, 1} M_{w, 1}+x_{s f, 2} M_{w, 2},
\end{aligned}
$$

where $M_{w, 1}, M_{w, 2}$ and $M_{w, 3}$ are the molecular weights of the ethanol $(46.07 \mathrm{~g} / \mathrm{mol})$, water $(18.02 \mathrm{~g} / \mathrm{mol})$ and $\mathrm{CaCl}_{2}(110.99 \mathrm{~g} / \mathrm{mol})$, respectively, and $M_{w}$ is the molecular weight of the binary mixture Equation (8).

We used the Electrolyte NRTL model to fit the experimental VLE data reported by Nishi [23] for the ethanol-water- $\mathrm{CaCl}_{2}$ mixture with $\mathrm{CaCl}_{2}$ concentration of $16.7 \mathrm{wt} \%$ on a salt-free basis; therefore, the composition of the salt in the distillation column stages should be kept as close as possible to this value.

The interaction parameters of the Electrolyte NRTL model serve to estimate the activity coefficients. Both the procedure for obtaining the model parameters and the final tuning of the thermodynamic model are presented in Section 2.1. The prediction of the $x y$ and Txy diagrams are depicted in Figure 3 and Table 2. The absolute mean error of estimation is 0.871129 for the temperature regression and $1.21765 \times 10^{-6}$ for the vapor composition fitting.
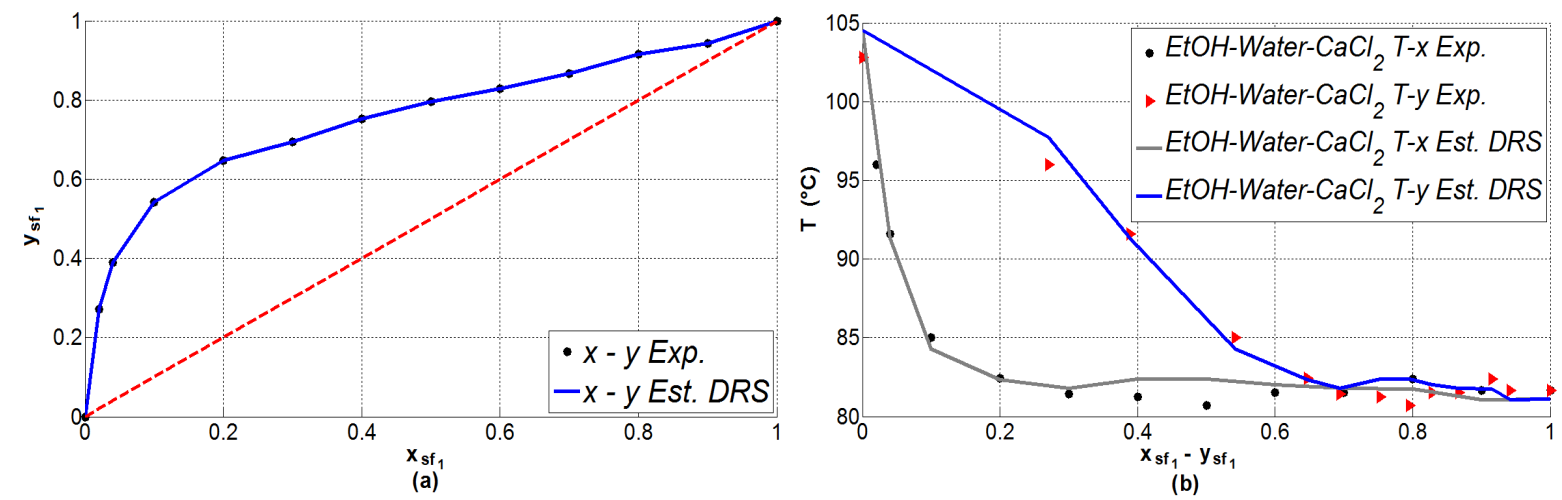

Figure 3. VLE of ethanol-water- $\mathrm{CaCl}_{2}$ system, expressed on a salt-free basis. (a) $x y$ diagram; (b) Txy diagram.

Table 2. Experimental $\left(y_{s f, 1, E x p}\right.$ and $\left.T_{E x p}\right)$ and estimated $\left(y_{s f, 1, E s t}\right.$ and $\left.T_{E s t}\right)$ VLE data of the ethanol-water- $\mathrm{CaCl}_{2}$ system for pressure of 1.01325 bar and $\mathrm{CaCl}_{2}$ concentration of $16.7 \mathrm{wt} \%$.

\begin{tabular}{ccccccc}
\hline $\boldsymbol{x}_{\boldsymbol{s f} \mathbf{1} \mathbf{1}}$ & $\boldsymbol{y}_{\boldsymbol{s f}, \mathbf{1}, \boldsymbol{E x p}}$ & $\boldsymbol{y}_{\boldsymbol{s f}, \mathbf{1}, \boldsymbol{E s t}}$ & $\boldsymbol{\Delta} \boldsymbol{y}_{\boldsymbol{s f}, \mathbf{1}}$ & $\boldsymbol{T}_{\boldsymbol{E x p}}$ & $\boldsymbol{T}_{\text {Est }}$ & $\boldsymbol{\Delta} \boldsymbol{T}_{\circ} \boldsymbol{C}$ \\
\hline 0 & 0 & 0 & 0 & 102.80 & 104.51 & 1.71 \\
0.02 & 0.271 & 0.271 & $6.90 \times 10^{-6}$ & 96.00 & 97.74 & 1.74 \\
0.04 & 0.389 & 0.389 & $2.49 \times 10^{-6}$ & 91.60 & 91.33 & 0.27 \\
0.10 & 0.542 & 0.542 & $2.41 \times 10^{-6}$ & 85.00 & 84.29 & 0.71 \\
0.20 & 0.647 & 0.647 & $3.13 \times 10^{-7}$ & 82.45 & 82.33 & 0.12 \\
0.30 & 0.694 & 0.694 & $1.25 \times 10^{-7}$ & 81.45 & 81.80 & 0.35 \\
0.40 & 0.753 & 0.753 & $4.70 \times 10^{-7}$ & 81.25 & 82.40 & 1.15 \\
0.50 & 0.795 & 0.795 & $4.16 \times 10^{-7}$ & 80.70 & 82.38 & 1.68 \\
0.60 & 0.828 & 0.828 & $1.41 \times 10^{-7}$ & 81.50 & 82.03 & 0.53 \\
0.70 & 0.867 & 0.867 & $4.02 \times 10^{-8}$ & 81.50 & 81.79 & 0.29 \\
0.80 & 0.915 & 0.915 & $7.86 \times 10^{-9}$ & 82.40 & 81.74 & 0.66 \\
0.90 & 0.942 & 0.942 & $8.14 \times 10^{-8}$ & 81.65 & 81.05 & 0.60 \\
\hline
\end{tabular}


The VLE of the nonideal ternary system is estimated as if it were a pseudo-binary mixture. The fact that there is a point at which bubble and dew point temperatures intersect in Figure 3 does not mean that an azeotrope arises, since the vapor and liquid do not coexist in the same composition. The point of intersection corresponds approximately to a temperature of $81.5^{\circ} \mathrm{C}$; in this condition the vapor and liquid compositions are 0.867 and 0.7 , respectively. This condition, experimentally determined, has been commented on in references [26,50].

\subsection{Steady-State Design}

We considered two well-known case studies of ethanol dehydration as a basis to design a saline extractive distillation pilot plant with $\mathrm{CaCl}_{2}$ as separating agent: the experimental study by Hashemi [27] and the steady-state modeling study by Llano-Restrepo and Aguilar-Arias [26], who estimated the ethanol-water- $\mathrm{CaCl}_{2}$ VLE using the Wilson-E and the NRTL-E models, respectively. Similarly to the industrial practice, these works considered the separation of a slightly pre-concentrated mixture.

As pointed out by Llano-Restrepo and Aguilar-Arias, the simulation of the process should be conducted by keeping the concentration of $\mathrm{CaCl}_{2}$ in the column as close as possible to $16.7 \mathrm{wt} \%$ on a salt free basis, since the experimental VLE data used to correlate the phase equilibrium model was obtained for this concentration [23]. A saturated vapor mixture of ethanol-water feeding the column should guarantee this condition; however, an appropriate salt flow should also enter at the top of the column. Llano-Restrepo and Aguilar-Arias developed a steady-state equilibrium model of a saline extractive distillation process and simulated a column with 22 equilibrium stages, treating $100 \mathrm{kmol} / \mathrm{h}$ of a mixture of $20 \%$ ethanol and $80 \%$ water on a molar basis, fed at $94.5^{\circ} \mathrm{C}$ and 1.01325 bar, a flow of $\mathrm{CaCl}_{2}$ equal to $8.315 \mathrm{kmol} / \mathrm{h}$ at $78.3^{\circ} \mathrm{C}$ keeps the salt concentration close to $16.7 \mathrm{wt} \%$. The two operating specifications are a reflux ratio of 6.42 and a distillate flow of $20 \mathrm{kmol} / \mathrm{h}$. We used their results to validate the ethanol dehydration simulation in Aspen-Plus, and the validation results are reported in Section 2.1.

Taking as a starting point the described process, we designed a distillation pilot plant with flow specification of $0.635 \mathrm{kmol} / \mathrm{h}$ or $15 \mathrm{~kg} / \mathrm{h}$, which is the minimum flow for a pilot plant production (according to a quotation of Sulzer Chemtech Ltd, Sulzerallee 48, 8404 Winterthur Switzerland). Moreover, a rough approximation of the column efficiency is also assumed for simulating the process, thereby the number of trays increases with respect to the original design. The column efficiency estimated from the empirical O'Connell correlation was 40\%; on the other hand, Barba et al. [19] estimated a column efficiency of $70 \%$ for a packed column with three sections. As a crude estimation, an intermediate value of efficiency was assumed (50\%).

We performed a sensitivity analysis using the rigorous distillation model to determine the total number of stages of the column and the feed tray for a reflux ratio of 6.42. Simulations were done with reflux ratios between 5 and 7 , in order to additionally investigate the influence of the operating conditions on both the product purity and energy consumption in the reboiler. Results provide useful insights for appropriately reconfiguring the column to different specifications of product or introducing energy consumption constrains, and for giving an early indication of the allowable tolerance to variation of the reflux ratio if desiring to conserve product quality within specifications. Thus, the results of the analysis are discussed to make evident the fulfillment of the described purposes.

We examined how the purity of the distillate product depends on the feed tray location for a different number of stages in the column, including the condenser and the column base, considering four reflux ratios: 5, 5.778, 6.420 and 7.062. We firstly present Figure 4 to show these relationships considering the nominal reflux ratio since the simulations with other reflux ratios have similar behaviors.

For a fixed reflux ratio and total number of stages, the relationship between purity and feed tray location is clearly nonlinear. The optimal stage for feeding the ethanol-water mixture is the tray for 
which the maximum purity is achieved. The feeding of the mixture before and after that tray produces purity drop, but the slope of the reduction curves is steeper for greater numbers of total stages.

Afterwards, the information extracted from the simulations carried out with different reflux ratios served to build Figure 5, which shows the location of the feed tray that allows the maximum ethanol purity in columns with total number of trays between 17 and 30. The corresponding reboiler heat duty is also showed. Different issues are discussed below.

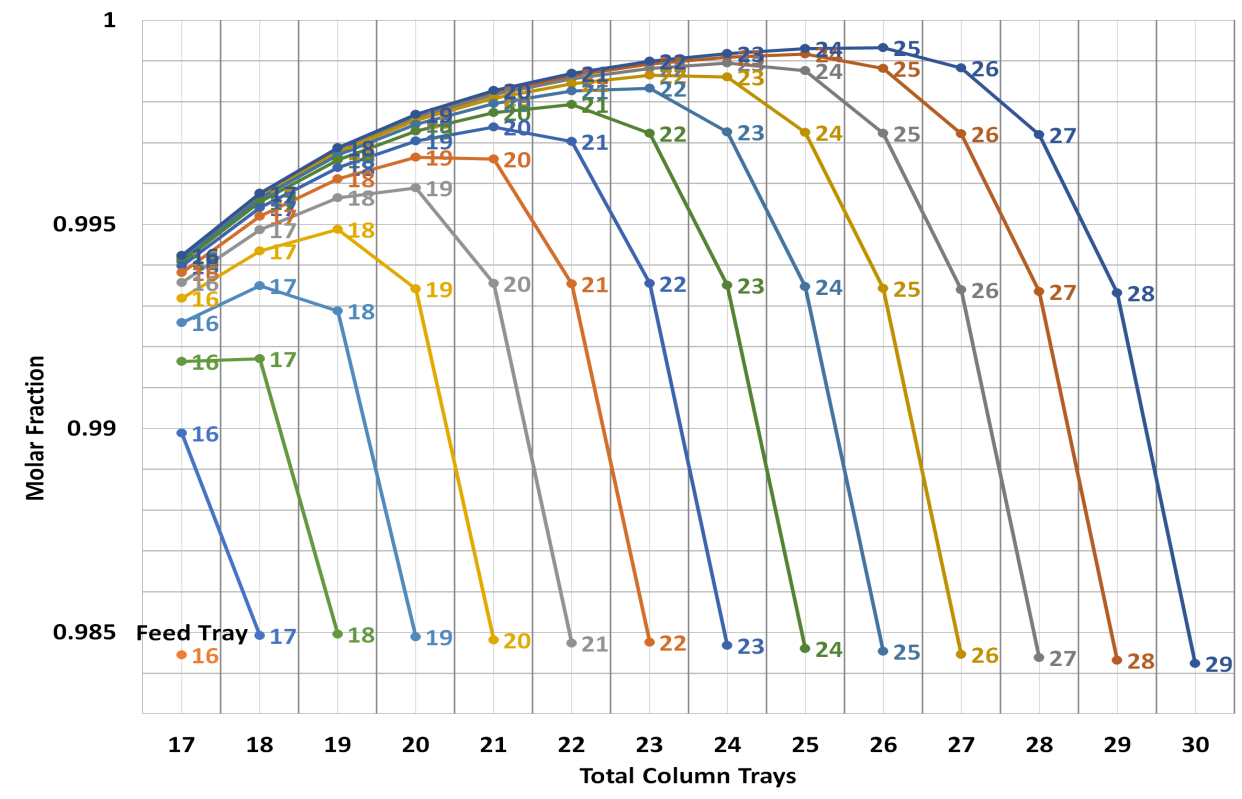

Figure 4. Influence of the feed tray location ( $x$-axis) on the ethanol purity ( $y$-axis), for different numbers of stages (from 17 to 30 , numbers varying over the curves). Case with reflux ratio equal to 6.42.

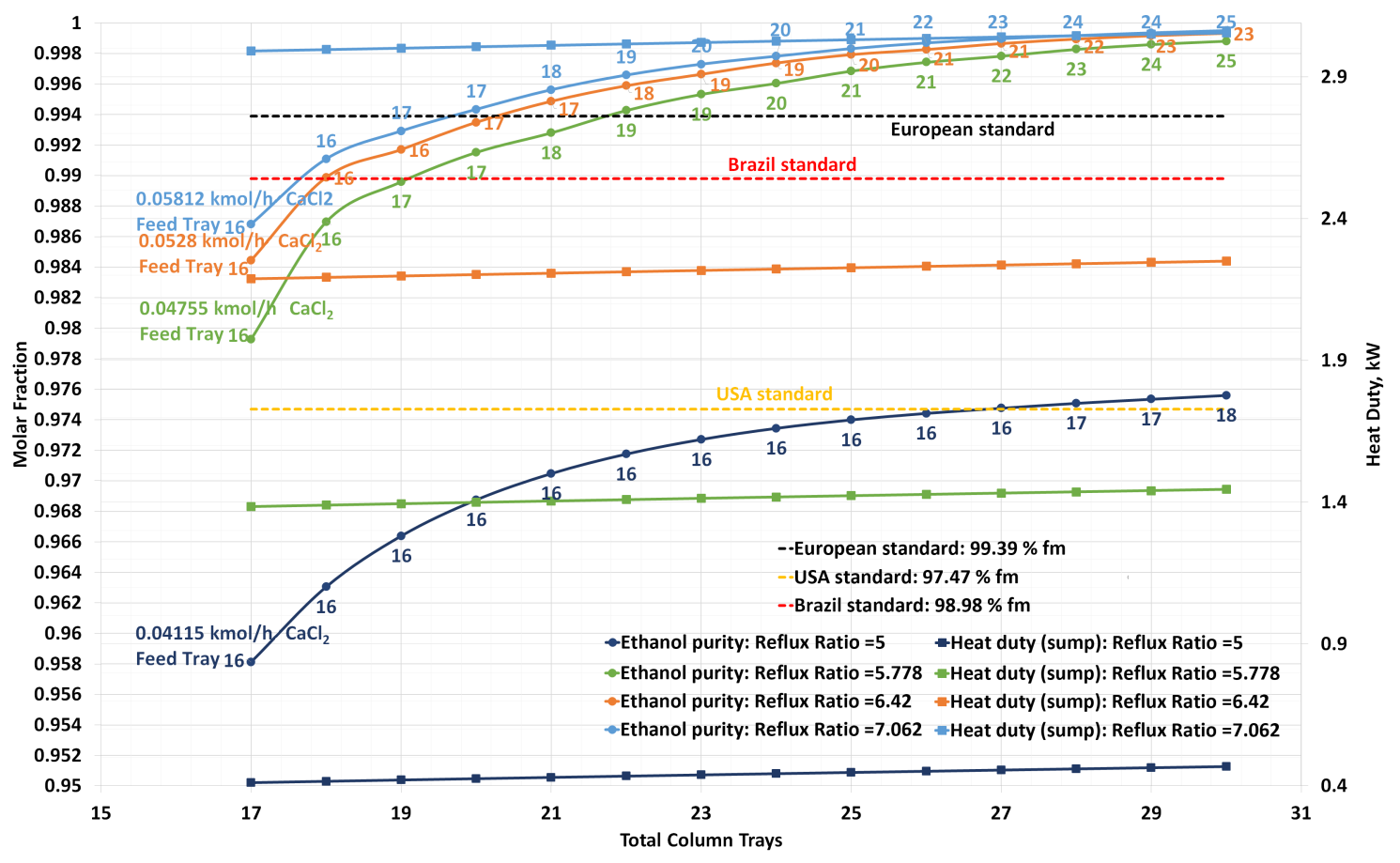

Figure 5. Maximum ethanol purity and the corresponding reboiler heat duty, obtained by considering the indicated feed tray, for different combinations of reflux ratio and total number of trays. 
The effect of the reflux ratio on the ethanol purity is nonlinear: the purity increases with the reflux ratio, but the growing trend slows down for large reflux ratios. Instead, the energy consumed in the reboiler augments proportionally to the reflux ratio. Thus, considering the design reflux ratio (6.42) as a baseline, the gain in the purity of the product is minor when increasing the reflux ratio from 6.42 to $7.062(0.066 \%)$, while the reboiler energy requirement augments to a larger extent $(36.5 \%)$. Then, a drop in product purity occurs when reducing the reflux ratio from 6.42 to $5.778(0.1316 \%)$, and the purity drop is stiffer as the reflux ratio diminishes, but the reboiler heat duty decreases by the same proportion (36.2\%). The percentages provided were computed by considering a column with minimum 23 trays, in order to fulfill the European standard even for a reflux ratio of 5.778 .

Both the purity of the product and the reboiler heat duty also depend on the total number of trays, but the effect of varying the number of trays is lower compared with the effect of changing the reflux ratio. For a constant reflux ratio, a larger number of total trays improves purity, but also increases the energy consumption.

A trade-off between purity and energy consumption should be established when defining the reflux ratio and the total number of trays, but an additional criterion is the fulfillment of technical specifications for fuel ethanol quality. The European standard (CEN EN 15376:2014, European Committee for Standardization) requires the ethanol to contain a maximum of $0.24 \mathrm{vol} \%$ water, the USA standard requires a maximum water content of $1 \mathrm{vol} \%$, whereas the Brazil ANP (National agency of petroleum) Resolution 36, $0.4 \mathrm{vol} \%$ [51]. Thereby, the considered minimum ethanol content product specifications are $99.76 \mathrm{vol} \%(99.39 \%$ mole), $99.0 \mathrm{vol} \%$ (97.47\% mole) and $99.6 \mathrm{vol} \%(98.98 \%$ mole), respectively.

Given a reflux ratio of 5 , the distillation provides a product with a maximum purity of 0.976 . The product meets the minimum ethanol content set by the American standard only with columns composed of at least 27 total stages. For higher values of reflux ratios, at least 22 stages are required to meet the three quality standards reported in this paper.

Given a reflux ratio of 6.42 , the three quality standards are met for a minimum of 22 stages, but the range of variation of the ethanol mole fraction would be very restrictive and would be difficult for achieving the operational objective of the control. Then, the decision is to use a column with 26 total stages, selecting tray 21 to feed the ethanol-water mixture to be treated.

Control structures that exhibit variation of the reflux ratio should not have a problem tolerating changes of at least $\pm 10 \%$ (from 5.778 to 7.062 ) of the nominal value because, in the operating region, the product purity is less sensitive to changes of the reflux ratio and the purity is quite high there; moreover, a large margin exists with respect to the quality standards. On the other hand, the reboiler heat duty, as mentioned before, is more affected by the reflux ratio changes. The process design is specified in Table 3, which includes the input nominal operating conditions. The flowsheet of the process is depicted in Figure 6. 
Table 3. Input data, specified parameters, and overall output data for the simulation of the saline extractive distillation column with $\mathrm{CaCl}_{2}$ as separating agent.

\begin{tabular}{lcc}
\hline Input/Output Data and Specified Parameters & Symbol & Value \\
\hline Input data and specified parameters & & \\
Number of equilibrium stages & $\mathrm{N}$ & 26 \\
Main feed stage & & 21 \\
Column efficiency $(\%)$ & & 50 \\
Main feed thermodynamic state & $\mathrm{T}_{F, 21}$ & Saturated vapor \\
Main feed temperature $\left({ }^{\circ} \mathrm{C}\right)$ & $\mathrm{F}_{21}$ & 0.635 \\
Main feed molar flow rate $(\mathrm{kmol} / \mathrm{h})$ & $\mathrm{z}_{1,21}$ & 0.2 \\
Main feed ethanol mole fraction & $\mathrm{z}_{2,21}$ & 0.8 \\
Main feed water mole fraction & $\mathrm{F}_{2}$ & 0.528 \\
Salt feed molar flow rate $(\mathrm{kmol} / \mathrm{h})$ & $\mathrm{T}_{F, 2}$ & 78.3 \\
Salt feed temperature $\left({ }^{\circ} \mathrm{C}\right)$ & $\mathrm{D}$ & 0.127 \\
Distillate molar flow rate $(\mathrm{kmol} / \mathrm{h})$ & & 6.42 \\
Reflux Ratio & $\mathrm{P}$ & 1.01325 \\
Operating pressure $($ bar $)$ & & \\
Output data & & \\
Ethanol molar flow rate in distillate $(\mathrm{kmol} / \mathrm{h})$ & $\mathrm{D}_{1,1}$ & 0.127 \\
Water molar flow rate in distillate $(\mathrm{kmol} / \mathrm{h})$ & $\mathrm{D}_{2,1}$ & 0.0017 \\
Condenser heat duty $(\mathrm{kW})$ & $\mathrm{Q}_{C}$ & -10.205 \\
Reboiler heat duty $(\mathrm{kW})$ & $\mathrm{Q}_{R}$ & 2.2319 \\
\hline
\end{tabular}

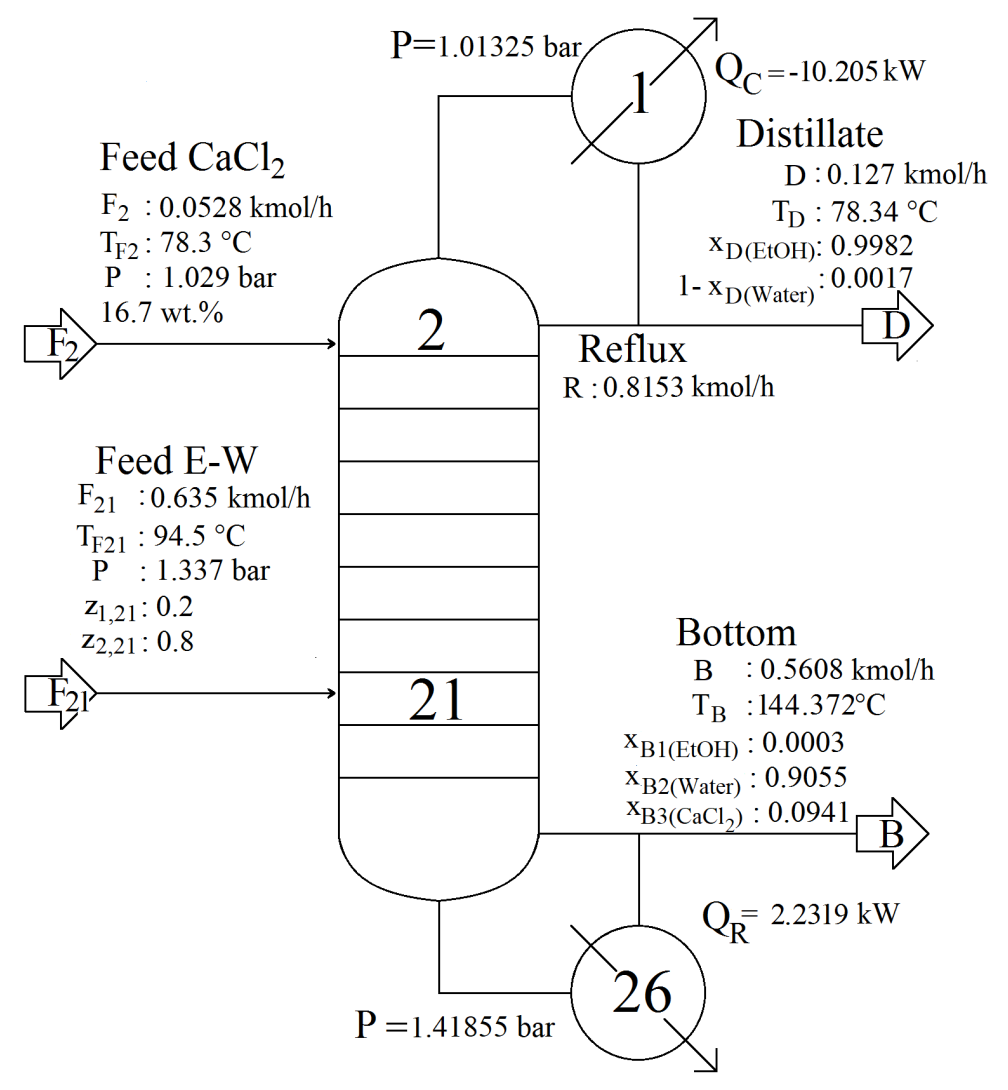

Figure 6. Nominal operating conditions of the salt extractive distillation pilot plant.

\section{Control Structures}

Chemical processes are nonlinear and multi-variable systems that certainly lead to quite complex control. In particular, control of two-products distillation columns is an ongoing study 
and remains an open problem. The steady-state degrees of freedom of distillation columns establishes a two-specification problem, whereas the dynamic degrees of freedom defines a $5 \times 5$ control problem. Whether the control problem is solved by a multi-variable approach or through a decentralized control scheme, interactions between variables and control loops always pose a challenge to meeting the regulatory targets in accordance with the plant operating requirements.

Key factors decided at the steady-state design level that influence the process control selection involve the product quality target; the process operating conditions, such as reflux ratio, column pressure and feed composition; energy consumption; and the column size and configuration. The control design of the salt extractive distillation process differs from a classical ideal binary distillation due to certain features of the plant:

- A nonlinear thermodynamic model is used for non-ideal VLE prediction of an electrolytic system.

- The ethanol-water- $\mathrm{CaCl}_{2}$ system is considered as a pseudo-binary mixture and apparent compositions are handled along with the distillation column conservation equations.

- An additional input current is introduced at the top of the column with the dissolved salt.

- A further degree of freedom is imposed by the addition of the salt, but it is assumed as an ideal control loop with the objective of adjusting the salt feeding flow as a function of the main feed, the products and the reflux change, in order to conserve a salt composition close to $16.7 \mathrm{wt} \%$ on a salt-free basis throughout the columns' trays.

The quality of the products is directly measured by the distillate and bottom compositions. For the present application, the distillate product composition is critical, and thus attempts are addressed to guarantee the distillate product quality. Due to the well-known problems associated with the measurement of the composition, it is a common practice to indirectly regulate the products compositions by controlling the temperature of certain tray(s) in the column. Indirect control of composition certainly implies an offset with respect to the set-point, but it should be sufficiently small to ensure the fulfillment of the quality standards.

The efficacy of the various temperature-based control strategies in distillation columns depends on the products specifications, operating conditions, column configuration, and column sizing. Most of the recommendations apply for classical ideal binary distillation, but even for this application, the task of choosing the control scheme is not evident. In this work, we evaluate a dual-temperature control approach based on the RV (reflux/boilup) structure; afterwards, we evaluate two different single temperature control approaches known as "single-end" structures. The single-end mode control uses one degree of freedom to control the temperature of a selected stage. The specification of the second degree of freedom enables different control configurations by choosing among a variety of relations; a constant reflux ratio (RR) and a constant reflux to feed ratio (R/F) specifications give the most common configurations. The tests presented in this work are mainly addressed to demonstrate and to compare the performances of the control structures by perturbation analysis.

Pressure, reflux drum level, and sump level controllers were installed to stabilize the column. The simulations of distillation columns in Aspen Dynamics presuppose the assumption of negligible thermal dynamics of the condenser and the reboiler, which is valid because of the faster thermal response, compared with other dynamics of the system. On the other hand, tank sizing makes available the dynamic capacitances that allow for determining the time constants of the equipment and predicting realistic flow dynamic responses of the condenser and the reboiler; then, introducing additional hydraulic lags is no longer needed. Therefore, we need to estimate and provide the dimensions of the tanks. Based on the heuristic relations proposed by Luyben [52], the dimensions were estimated as follows for hold-ups of $10 \mathrm{~min}$ : the reflux drum (in Aspen Plus, it combines the condenser and reflux drum) has a diameter of $18.5 \mathrm{~cm}$ and a height of $38.5 \mathrm{~cm}$, and the sump has a diameter of $10.6 \mathrm{~cm}$ and a height of $21.5 \mathrm{~cm}$.

Additionally, the temperature on the column trays is not immediately affected by input changes because the sensor response gives rise to a delayed dynamic. To introduce the measurement delay 
within the temperature control loop, a lag is installed, and it could be particularly necessary if the sensor location is close to the column bottoms. According to literature recommendations [52], two first order lags with time constants of $0.5 \mathrm{~min}$ is a reasonable assumption within a temperature control loop. The same author proposes a distillation control example assuming two first order lags with time constants of $1 \mathrm{~min}$. In this work, we consider similar delays caused by temperature measurements, but instead of introducing two first order lags, we introduce a first order lag with time constants close to $2 \mathrm{~min}$.

\subsection{Dual Temperature Control Structure}

\subsubsection{Stages for Sensor Locations in Dual-Temperature Control}

We examined the following criteria to deal with the stage location for temperature control: we firstly used the criteria of maximum slope variation in the temperature profile. A steady-state simulation was performed by introducing the nominal inputs to obtain the temperature profile stage to stage throughout the column. The maximum slope corresponds to the most rapid temperature change from tray to tray and determines the sensor location. The ethanol-water- $\mathrm{CaCl}_{2}$ column presents low temperature variation from the upper part to stage 17, thus even if it is not recommended to select a sensor location close to the feed tray, stages 20 and 22 show the maximum slopes (Figure 7a,b).
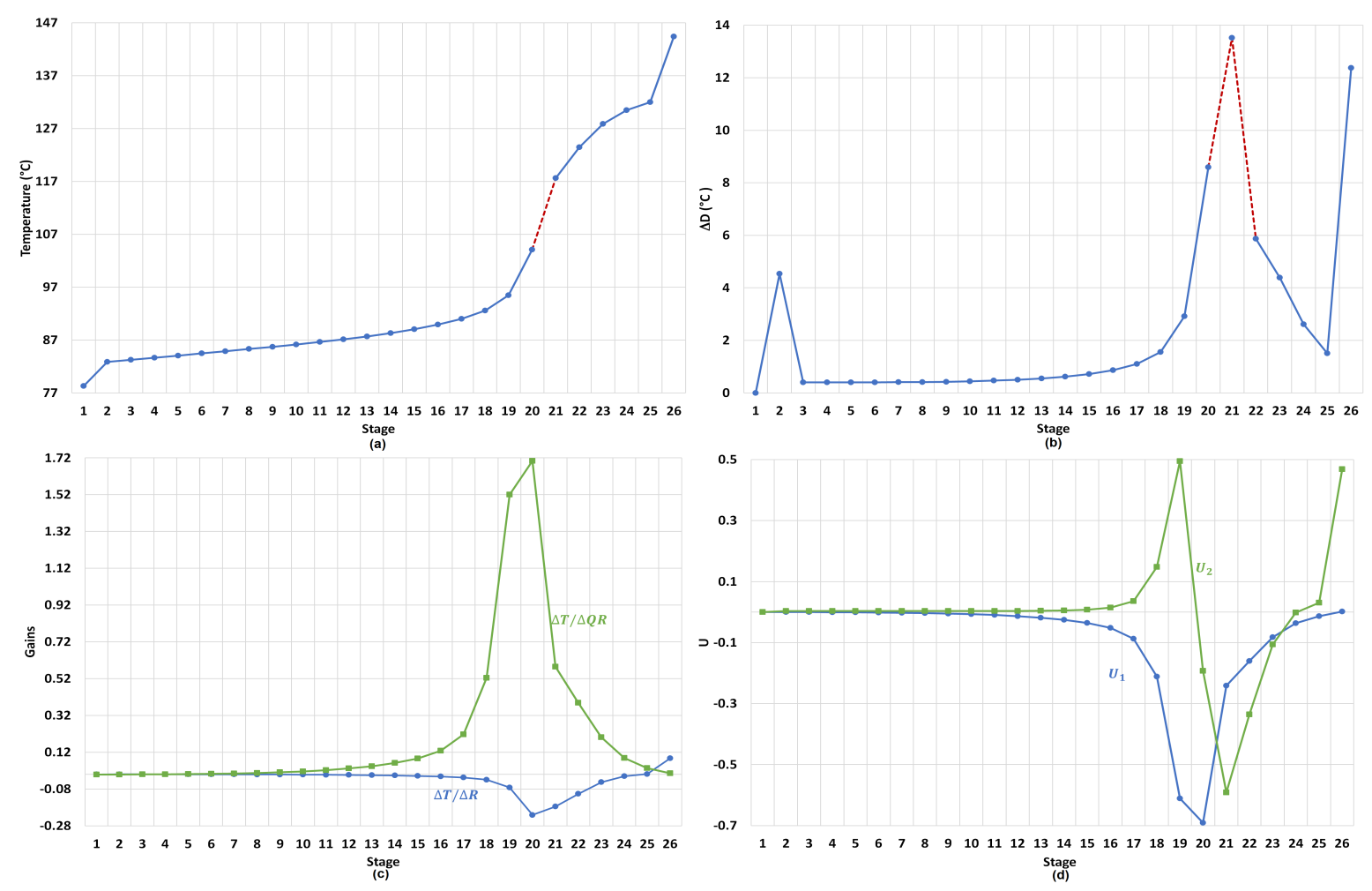

Figure 7. Sensor location for temperature control (a) temperature profile; (b) temperature change stage to stage; (c) sensitivity analysis gains; and (d) left singular vectors $U_{1}$ and $U_{2}$ calculated from the singular value decomposition (SVD) analysis vs. stage location.

The sensitivity criteria implies changing the manipulating variables to measure the effects on the temperature, stage to stage. For a dual temperature control, the influence of the reflux and the reboiler heat duty on the temperature all over the column was measured, then represented in a gain matrix $G$. A change of $0.3 \%$ in the reboiler heat duty and a change of 3\% in the reflux flow rate were introduced and their influence on the temperature profile was determined and plotted (Figure 7c). The analysis results suggest that changes to the reflux flow rate affect stage 20 more than they affect the rest of the 
column, whereas changes to the reboiler heat duty affect stages 18 to 22 , but only stage 22 is placed below the feed.

To complete the criteria for sensor location, the singular value decomposition (SVD) criteria was performed for the gain matrix $G$, and this analysis is a factorization into the product of three matrices: $G=U S V^{T}$, where $G$ and $U$ give information about sensitivity and sensors interaction and $U$ is composed of $U_{1}$ and $U_{2}$ columns. The absolute maximum value of the $U_{1}$ vector indicates the more sensitive location for a temperature sensor, whereas the $U_{2}$ vector indicates a second sensitive location with the least possible interaction with the first one [53] (Figure 7d). For the case of the ethanol-water- $\mathrm{CaCl}_{2}$ column, simulations let us conclude that the appropriate sensors placements are stage 20, above the feed plate (corresponding to the largest value of $U_{1}$ vector) and 22 (corresponding to the largest value of $U_{2}$ vector, placed under the feed plate).

The condition number $(\mathrm{CN})$ calculated from the SVD of the overall gain matrix $G$ as the ratio of the largest singular value to the lowest singular value is equal to 13.29 , whereas the $\mathrm{CN}$ related to the dual temperature control problem is equal to 33.27. These $\mathrm{CN}$ values indicate that the dual temperature control problem may be somewhat more demanding than it has been pointed out by the condition number derived from the global gain matrix, but it should be yet manageable by selecting stages 20 and 22 as the sensor placement.

According to the assumption of temperature measurement delays represented by first order lags, the first lag with time constant $2 \mathrm{~min}$ is installed in the loop with temperature control on tray 20, whereas a second lag with a time constant of $2.2 \mathrm{~min}$ is installed in the loop with temperature control on tray 22.

\subsubsection{Reflus/Boilup Structure for Dual Temperature Control}

We consider the RV configuration because it is the most common choice for handling inputs in the industry, even if it is not necessarily the best control strategy. In fact, it has been shown that a closed-loop system with RV configuration can be very sensitive to variation in inputs [54].

The tuning of two temperature control loops is a more difficult problem owing to the interaction between the two control loops; however, for the study case, the calculated $\mathrm{CN}$ suggest that the dual temperature control is rather possible. Dual temperature loop is usually advised for medium and high input concentrations, whether the control can not be solved with a single-end mode, but this structure is also advised when high purity is desired in both products [28].

The regulatory control structure has the control loops as follows (Figure 8):

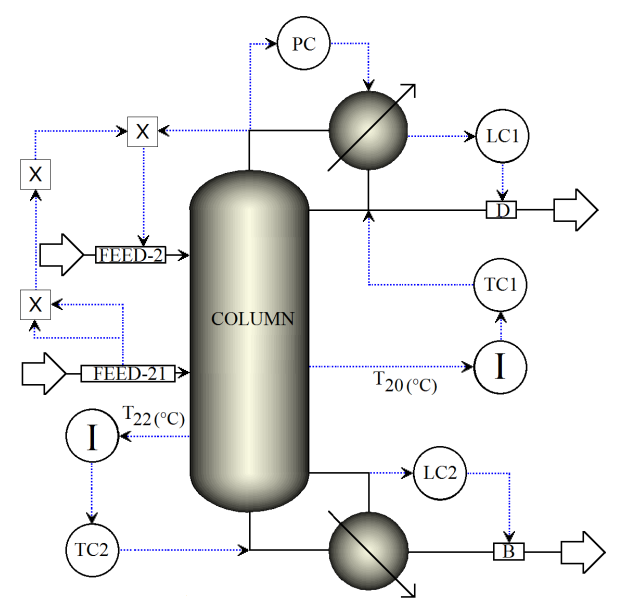

Figure 8. Structure RV with dual temperature control. 
1. TC1 loop: The reflux is used to regulate the temperature in tray 20 .

2. TC2 loop: The reboiler heat duty is used to regulate the temperature in tray 22 .

3. PC loop: The condenser pressure is controlled by manipulating the condenser duty.

4. LC1 loop: The reflux-drum level is regulated by manipulating the distillate flow.

5. LC2 loop: The base level is regulated by manipulating the bottoms flow.

6. FEED-2 loop: The fresh salt feed to the column is an ideal flow control of the dissolved salt with the operational objective of keeping the concentration of the salt in the column stages as close as possible to $16.7 \mathrm{wt} \%$ (to preserve VLE estimation validity). The salt feed flow is calculated online in terms of the feed, distillate flows and the reflux.

The five proportional-integral-derivative (PID) controllers were tuned in closed loop using the Ziegler-Nichols method. Where $K_{C}, \tau_{I}$, and $K_{D}$, all non-negative, denote the coefficients for the proportional, integral, and derivative terms, respectively, calculated as shown in Table 4.

Table 4. Proportional-integral-derivative (PID) controllers gains for dual temperature control.

\begin{tabular}{llccccc}
\hline \multicolumn{2}{l}{ Controller } & PC & LC1 & LC2 & TC1 & TC2 \\
\hline $\mathrm{P}$ & $K_{C}$ & 13.9 & 74.4 & 1616 & 1.9 & 58.9 \\
$\mathrm{I}$ & $\tau_{I}$ & 2.4 & 1.2 & 0.6 & 6.9 & 2.7 \\
$\mathrm{D}$ & $K_{D}$ & 0.6 & 0.3 & 0.15 & 1.73 & 0.68 \\
\hline
\end{tabular}

\subsection{Control of a Single Tray Temperature}

\subsubsection{Reflux Ratio Structure for Single Temperature Control}

For the case of diluted feed and high purity product, the reflux flow rate is quite larger than the distillate flow rate; under these conditions, the reflux-drum level is controlled with the reflux flow rate. The temperature in the selected stage (20) is controlled with the heat of the reboiler and the distillate flow rate is rationed to the reflux flow rate. It is said that this structure allows for properly regulating one of the two products of the column, following the location of the temperature sensor [28]. However, this was not the case for us, and, later, we will show that both products were kept within an acceptable range of purity despite the fact that the selected locations of the temperature control were closer to the column base. In fact, low temperature sensitivity was observed in the rectifying section of the column.

The regulatory control structure has the control loops as follows (Figure 9):

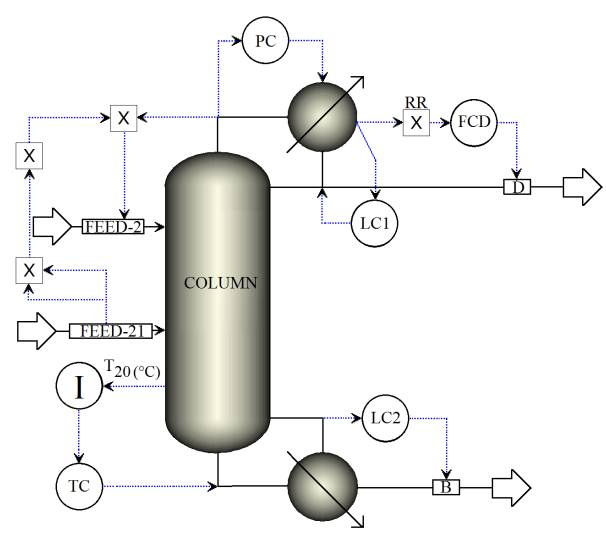

Figure 9. Structure RR with single tray temperature control.

1. FCD loop: The distillate flow rate is rationed to the reflux flow rate.

2. LC1 loop: The reflux-drum level is regulated by manipulating the reflux. 
3. LC2 loop: The base level is regulated by manipulating the bottoms flow.

4. PC loop: The condenser pressure is controlled by manipulating the condenser duty.

5. TC loop: The reboiler heat is used to regulate the temperature in tray 20.

6. FEED-2 loop: The fresh salt feed to the column is an ideal flow control of the dissolved salt with the operational objective of keeping the concentration of the salt in the column stages as close as possible to $16.7 \mathrm{wt} \%$ (to preserve VLE estimation validity). The salt feed flow is calculated online in terms of the feed, distillate flows and the reflux.

The five proportional-integral (PI) controllers were tuned in closed loop using the Ziegler-Nichols method. The calculated gains are shown in Table 5.

Table 5. Proportional-integral (PI) controllers gains for single temperature control.

\begin{tabular}{llccccc}
\hline Controller & PC & LC1 & LC2 & TC1 & FCD \\
\hline $\mathrm{P}$ & $K_{C}$ & 32.9 & 640 & 141 & 121.1 & 0.63 \\
$\mathrm{I}$ & $\tau_{I}$ & 2.5 & 1 & 1 & 1.5 & 2 \\
\hline
\end{tabular}

\subsubsection{Reflux to Feed Ratio Structure for Single Temperature Control}

Two critical loops of this configuration are the level control of the reflux-drum and the temperature control of the selected stage. Usually, the first one is controlled by the distillate flow rate and the second is controlled by the reboiler heat input. In this structure, the reflux flow rate is rationed to the feed flow rate. For the case of diluted feed and high purity product, the reflux flow rate is much larger than the distillate flow rate; under these conditions, control of the reflux drum level can produce significant variations in the distillate flow rate, affecting, for example, a second unity with large load disturbances. The idea is then to avoid controlling the level of the reflux-drum with the distillate. A modified structure was proposed in [28], and the reboiler heat input is selected as the manipulated variable to control the level of the reflux-drum. This is possible because vapor boilup has an immediate and strong effect on the level of the reflux-drum. However, this change means that heat is no longer available from the reboiler to control the temperature of the selected stage. The distillate flow rate is then selected as a manipulated variable to control the temperature. In fact, temperatures in the column trays are directly affected by vapor boilup and the reflux flow rate, whereas the flow rate of the distillate only affects the temperature indirectly through the level control of the reflux-drum. Thus, there exits a strong dependence between these controllers: the level control establishes the response time as the temperature control is adjusted in response to changes in level of the reflux-drum. We decided to use this modified R/F configuration.

The regulatory control structure has the control loops as follows (Figure 10):

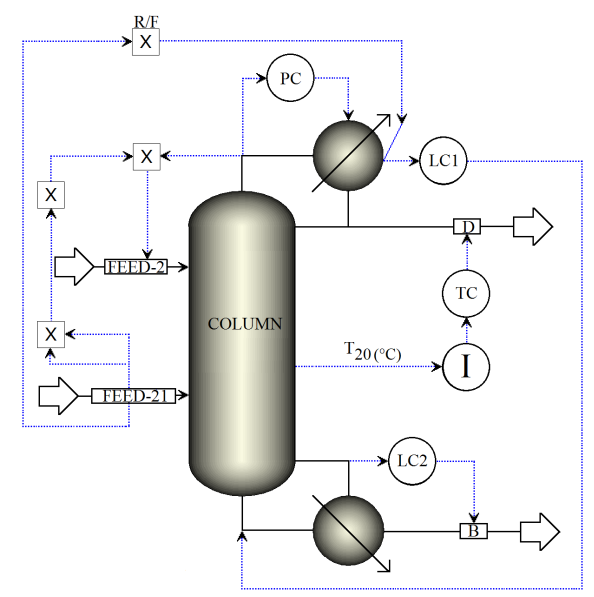

Figure 10. Structure R/F with single tray temperature control. 
1. R/F loop: The flow rate of the reflux is rationed to the feed flow rate.

2. LC1 loop: The reflux-drum level is regulated by manipulating the reboiler heat.

3. LC2 loop: The base level is regulated by manipulating the bottoms flow.

4. PC loop: The condenser pressure is controlled by manipulating the condenser duty.

5. TC loop: The distillate flow is used to regulate the temperature in tray 20.

6. FEED-2 loop: The fresh salt feed to the column is an ideal flow control of the dissolved salt with the operational objective of keeping the concentration of the salt in the column stages as close as possible to $16.7 \mathrm{wt} \%$ (to preserve VLE estimation validity). The salt feed flow is calculated online in terms of the feed, distillate flows and the reflux.

The four PID controllers were tuned in closed loop using the Ziegler-Nichols method. The calculated gains are shown in Table 6.

Table 6. PID controllers gains for single temperature control.

\begin{tabular}{llcccc}
\hline \multicolumn{2}{l}{ Controller } & PC & LC1 & LC2 & TC1 \\
\hline $\mathrm{P}$ & $K_{C}$ & 20 & 408 & 269.4 & 4.6 \\
$\mathrm{I}$ & $\tau_{I}$ & 1.2 & 0.9 & 43.2 & 4.5 \\
$\mathrm{D}$ & $K_{D}$ & 0.3 & 0.225 & 10.8 & 1.125 \\
\hline
\end{tabular}

\section{Evaluation of Control Structures: Results and Discussion}

The control structures were evaluated assuming two types of perturbations: step changes and continuous fluctuations emulated as the sum of sinusoidal functions with different frequencies. The first series of tests was performed considering perturbations in the feed composition (considering changes of $\pm 10 \%$ of the nominal feed composition and continuous oscillations represented in Figure 11a) - then with perturbations in the feed flow rate (considering changes of $\pm 8 \%$ of the nominal feed flow rate and continuous oscillations represented in Figure 11b) and finally with simultaneous perturbed inputs, combining feed flow and feed composition oscillations.
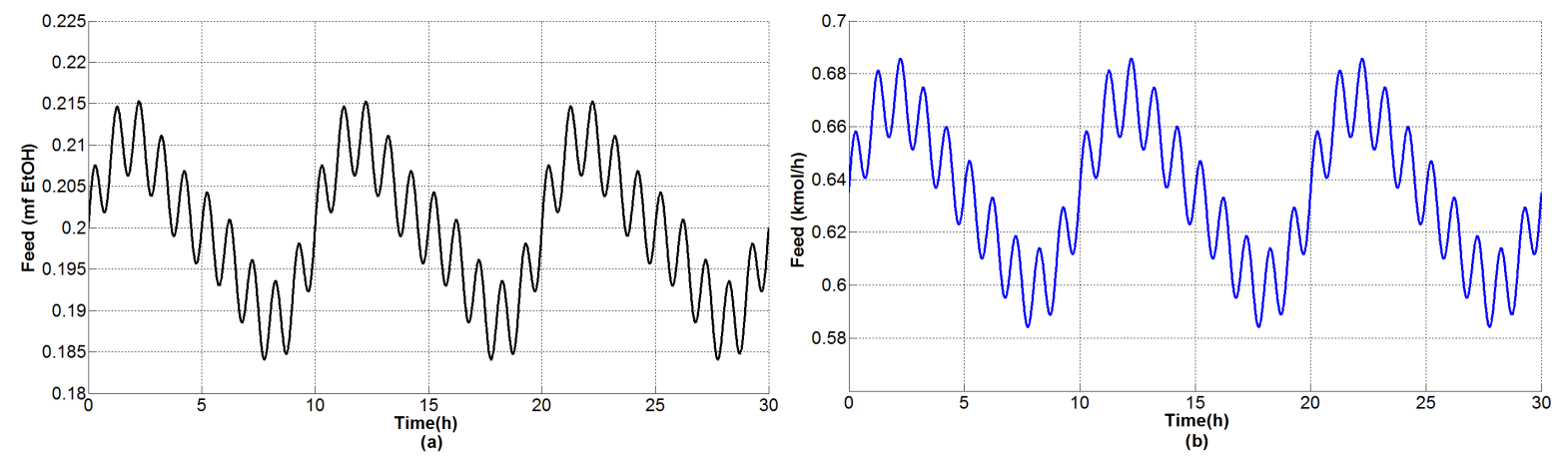

Figure 11. Continuous fluctuating perturbation on (a) feed ethanol composition and (b) feed flow rate.

\subsection{Performance of the Dual and Single-End Mode Temperature Control Structures}

The key objective of the specified control structures is to regulate the temperature of one or two trays; however, the main operational target is to meet ethanol purity standards throughout the operating time. With this in mind, we evaluated the performance of the control structures by measuring the effectiveness of the indirect control of the distillate composition. We established the performance assessment in terms of common error-integral criteria; specifically, we used the integral squared error (ISE); the integral absolute error (IAE) and the integral time-weighted absolute error (ITAE), along with classical performance measurements such as overshoot $\mathrm{M}_{p}$, peak time $\left(\mathrm{t}_{p}\right)$, rise time 
$\left(t_{1}\right)$ and settling time $\left(t_{s}\right)$; furthermore, reboiler energy consumption measurement complemented the control structures ating.

It should be considered that indirect control of composition necessarily produces a bias with respect to the reference, which can be seen as a permanent error that establishes a new unwanted steady state. Thus, the estimation of this bias is also taken into account to complete the characterization of the control structures performance $\left(\right.$ Bias $=\left[\operatorname{composition}_{\text {Reference }}-\right.$ composition $\left.\left._{\text {New Steady-State Signal }}\right] \times 10^{3}\right)$.

The evaluation criteria should give information of the transient response of the closed loop system under sudden load disturbances, set-point changes or under continuous fluctuations close to the nominal operating condition (caused by oscillating inputs, poor control tuning, interactions or mechanical devices vibration). In what follows, we define in this sense the interpretation of the performance indicators and we clarify how they are used.

ISE integrates the square of the error over time; therefore, its value grows as the error is larger, but it does not capture small persistent errors. Large ISE values can be interpreted as significant errors with respect to the reference. Likewise, IAE simply integrates absolute errors. Because these indexes essentially provide information about the deviations of the measured signal from a reference value, we use these criteria to determine which control structure keeps the distillate composition closest to the nominal purity requirement.

On the other hand, ITAE integrates the absolute error multiplied by the time over simulation time; as a result, large ITAE values can be interpreted as persistent oscillation in the system. Simulations showed that perturbations in the feed composition lead the distillate composition to oscillate in the vicinity of a new steady-state. In order to take both into account, the presence of fluctuating behavior and consistent offset, here, the error is calculated in two ways: it is the difference between the new steady-state and the composition signal over time $\left(\mathrm{ITAE}_{n s s}\right)$, or it is the difference between the reference and the composition signal over time $\left(\mathrm{ITAE}_{\text {set }}\right)$.

\subsubsection{Tests under Perturbations on the Feed Composition}

The first series of simulations corresponds to the evaluation of the control structures assuming changes on the feed composition. The control performance is presented as temporal plots of the ethanol molar fraction in the distillate, $x_{D}$ and the bottom products $x_{B}$, the controlled temperature(s) $T_{20}$ and $T_{22}$, the flows of dissolved $\mathrm{CaCl}_{2}(\mathrm{kmol} / \mathrm{h})$ salt, the distillate $D$ and the bottom $B$ products (see Figures 12-14). Afterwards, the control performance is evaluated by means of typical error criteria, along with classical performance measurements and energy consumption comparison (Figure 15).

The assessment of the control performance based on integral-error criteria is summarized in Table 7.

The RV structure delivers the highest bias, ISE, IAE and ITAE indexes, demonstrating poorer performance if compared with single temperature control strategies. In addition, down step-type disturbances generate larger ITAE $_{n s s}$ values owing to the markedly oscillating response of the controller. On the other hand, growing step disturbances produce larger ITAE $\mathrm{E}_{\text {set }}$ because, in this case, the steady-state error affects the plant more adversely than the fluctuating controller response.

The RR structure offers intermediate values of bias, ISE, IAE and ITAE, but confirmed that the steady-state errors are closer to those obtained with the RV configuration, whereas the fluctuating controller response is more approximated to the response of the R/F structure. Additionally, growing step-type disturbances provides $\mathrm{ITAE}_{n s s}$ as larger as $\mathrm{ITAE}_{\text {set }}$, meaning that the steady state error is not so different for positive and negative perturbations, thereby detecting consistently oscillating behavior from $\mathrm{ITAE}_{n s s}$ and $\mathrm{ITAE}_{\text {set }}$ measurements.

The R/F structure is advantageous because it generates lower bias than RV and RR structures, which is confirmed by the smallest ISE and IAE values. Generally, the nonlinear behavior of the plant produces a bias on the distillate composition with different amplitude, depending on whether changes in feed composition are made towards larger or a smaller values. However, the R/F control structure has comparable offsets, regardless of whether positive or negative steps are introduced as 
perturbations. Simulations conducted with feed composition changing down result in ISE and ITAE set $_{\text {s. }}$ to some extent larger than the same indicators obtained for positive feed composition changes. These indicators imply control responses with greater peaks and more oscillating behavior, respectively.

Criteria in Table 8 are suitable for evaluating the control performance in set-point changes, so we measured these indexes during the step perturbations tests. The most important thing to note is that, in both cases, positive or negative perturbations, the R/F structure is stabilized first. The rest of the indicators-the maximum overshoot, the time in which overshoot occurs and the rise time-are very similar for the three structures. Perhaps we can highlight the R/F structure when a positive disturbance occurs, and its response is slower and weaker.

Monitoring the reboiler heat duty during closed-loop operation (Figure 15) reveals that, under feed composition changes, the three control structures keep an average intake of energy close to $2.23 \mathrm{~kW}$, thereby maintaining the nominal value, so that there is not a net increase in energy consumption in the plant. However, fluctuating feed composition generates greater heat duty variations around the nominal value than step perturbations. For step perturbations, the energy consumption is directly proportional to the feed composition changes. With regard to the control strategy, the RV and the RR structures afford low variation of the reboiler heat duty, whereas R/F structure gives rise to faster and larger deviations, but they are still in the vicinity of the nominal condition. Simulation results agree with the observations concerning the steady-state design: firstly, the influence of the reflux ratio on the distillate purity is smoother at high distillate compositions. Secondly, for constant reflux ratio (or with small changes), small distillate composition deviations produce small changes in the reboiler energy. Greater reboiler heat duty alterations should be associated with lower feed composition values; nevertheless, the general effectiveness of the control strategy should decrease because it would not be necessarily appropriate for modest feed compositions. 

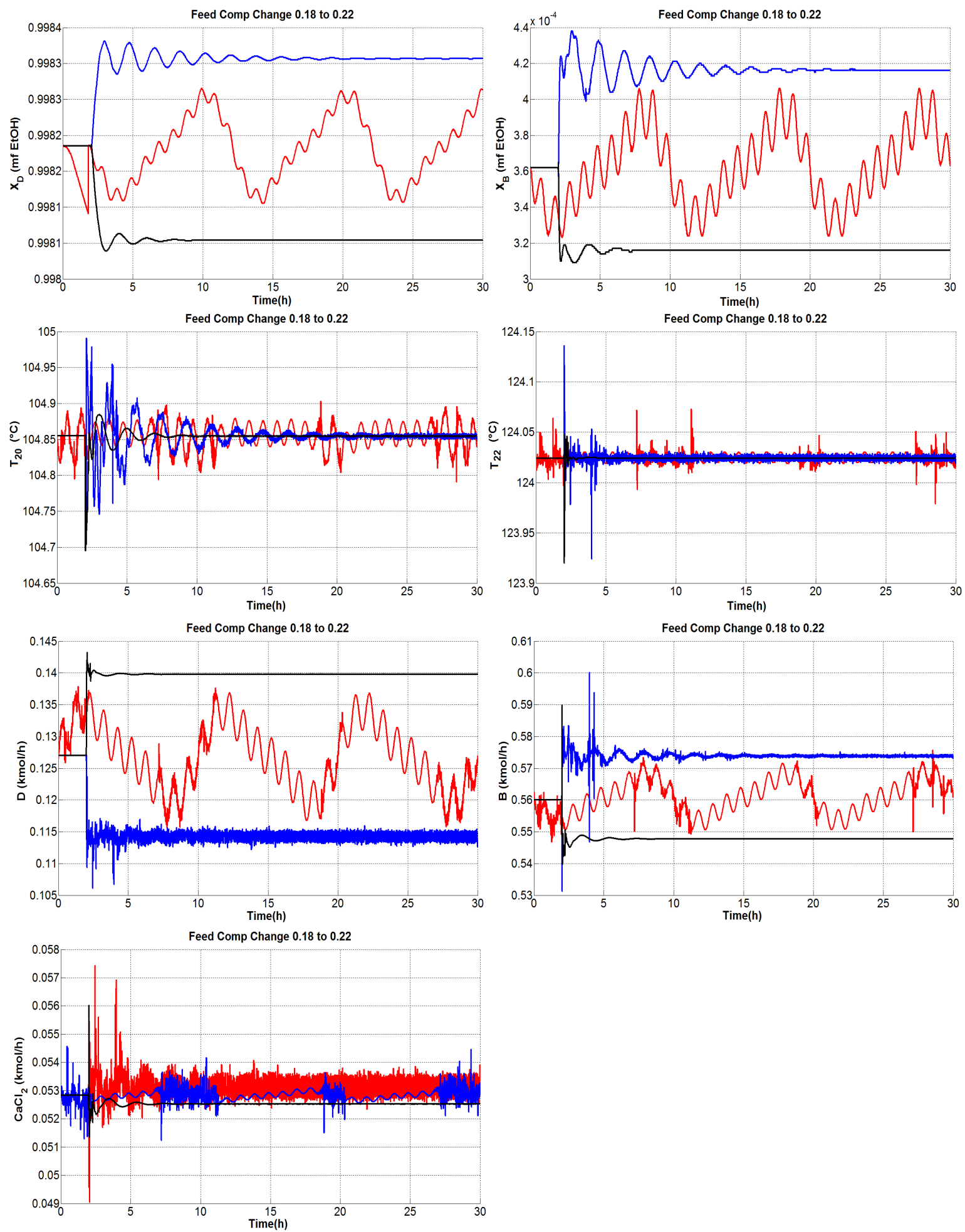

Figure 12. Performance of the RV structure for dual temperature control assuming step perturbations of the feed molar fraction with amplitude of $10 \%$ (black) and $-10 \%$ (blue) with respect to the nominal value, and a continuous fluctuating perturbation (red). 



Figure 13. Performance of the RR structure for single-end mode temperature control, assuming step perturbations of the feed molar fraction with amplitude of $10 \%$ (black) and $-10 \%$ (blue) with respect to the nominal value, and a continuous fluctuating perturbation (red). 

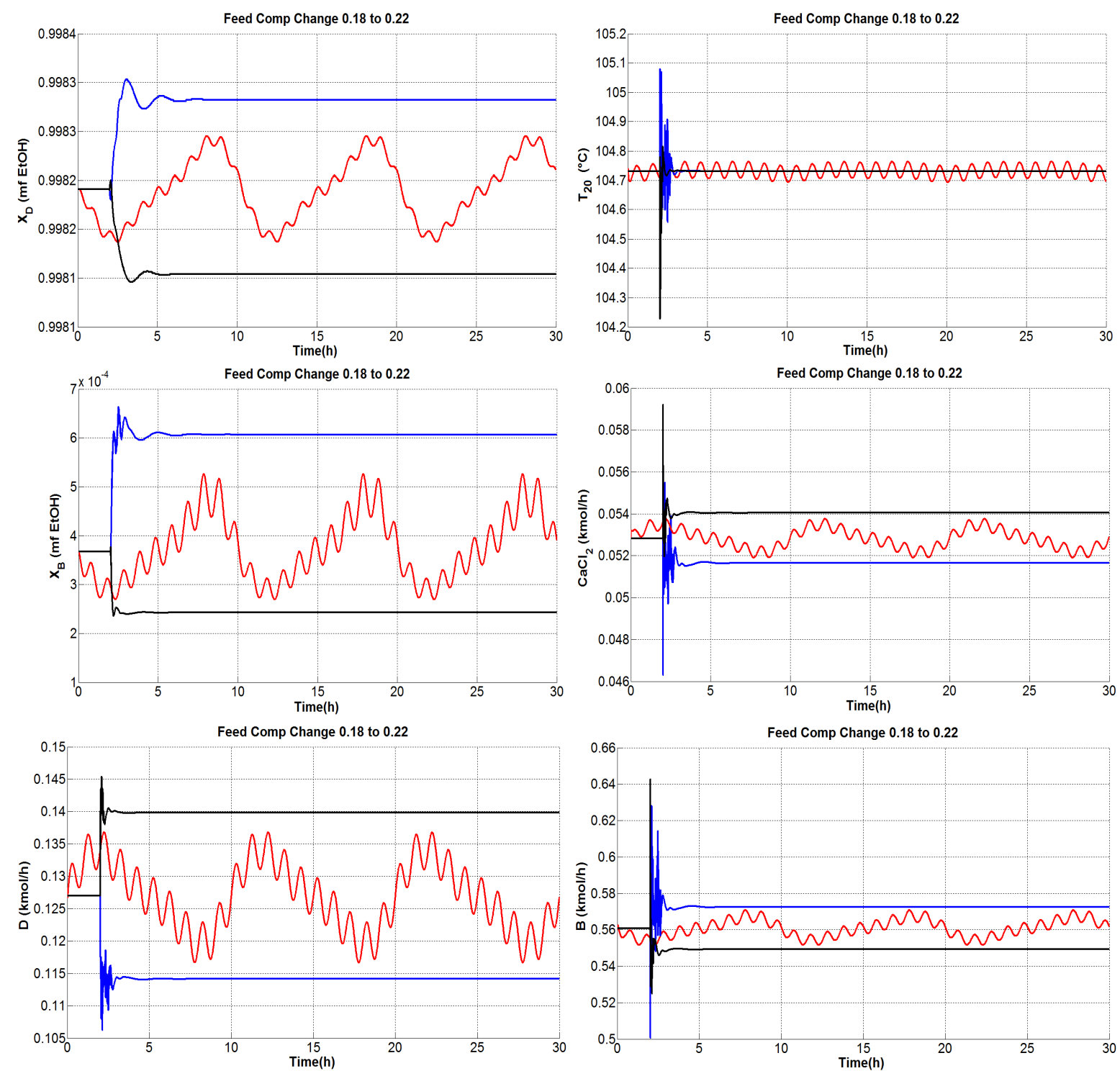

Figure 14. Performance of the R/F structure for single-end mode temperature control, assuming step perturbations of the feed molar fraction with amplitude of $10 \%$ (black) and $-10 \%$ (blue) with respect to the nominal value, and a continuous fluctuating perturbation (red).

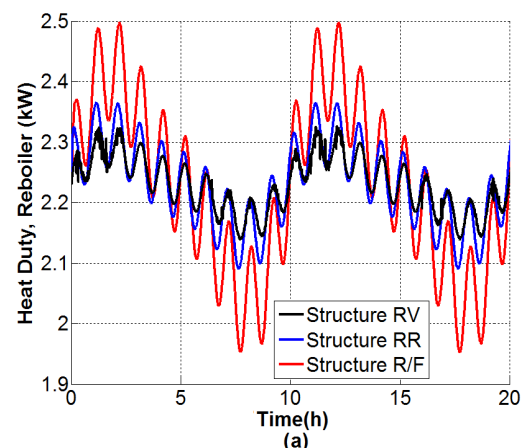

(a)



(b)

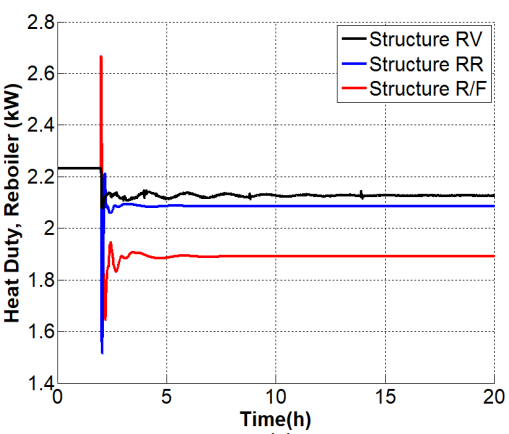

(c)

Figure 15. Reboiler energy consumption of the RV, RR and R/F control structures, assuming feed composition perturbations with (a) fluctuating input signal; (b) step of $10 \%$; and (c) step of $-10 \%$. 
Table 7. Performance indicators of control structures—case of feed composition perturbations.

\begin{tabular}{|c|c|c|c|c|c|c|c|}
\hline Structure & Perturbation & $\operatorname{Bias}\left(\times 10^{3}\right)$ & ISE $\left(\times 10^{6}\right)$ & IAE & ITAE $_{\text {set }}$ & ITAE $_{n s s}$ & Average Heat Duty reboiler $(\mathrm{kW})$ \\
\hline \multirow[b]{3}{*}{ RV } & Step $(+10)$ & 0.131 & 47.40 & 0.363 & 5.863 & 0.045 & 2.328 \\
\hline & Step $(-10)$ & -0.122 & 41.20 & 0.338 & 5.448 & 0.108 & 2.134 \\
\hline & Sinusoidal & & 6.430 & 0.120 & 1.820 & & 2.231 \\
\hline \multirow[b]{3}{*}{$\mathbf{R R}$} & Step $(+10)$ & 0.124 & 42.35 & 0.343 & 5.546 & 0.040 & 2.369 \\
\hline & Step $(-10)$ & -0.116 & 37.16 & 0.321 & 5.190 & 0.038 & 2.095 \\
\hline & Sinusoidal & & 5.854 & 0.114 & 1.735 & & 2.231 \\
\hline \multirow[b]{3}{*}{$\mathrm{R} / \mathrm{F}$} & Step $(+10)$ & 0.081 & 18.04 & 0.224 & 3.623 & 0.028 & 2.550 \\
\hline & Step $(-10)$ & -0.097 & 26.16 & 0.269 & 4.343 & 0.036 & 1.913 \\
\hline & Sinusoidal & & 3.281 & 0.085 & 1.334 & & 2.230 \\
\hline
\end{tabular}

Table 8. Characteristics of the controller response-case of feed composition perturbation.

\begin{tabular}{clcccr}
\hline Structure & Perturbation & $\mathbf{M}_{\boldsymbol{p}}\left(\times \mathbf{1 0}^{\mathbf{6}}\right)$ & $\mathbf{t}_{\boldsymbol{p}} \mathbf{( h )}$ & $\mathbf{t}_{1}(\mathbf{h})$ & $\mathbf{t}_{\boldsymbol{s}} \mathbf{( h )}$ \\
\hline \multirow{2}{*}{$\mathbf{R V}$} & Step $(+10)$ & -15 & 1.05 & 0.73 & 7.20 \\
& Step $(-10)$ & 21 & 1.05 & 0.60 & 18.53 \\
\hline \multirow{2}{*}{$\mathbf{R} \mathbf{R}$} & Step $(+10)$ & -12 & 1.10 & 0.79 & 4.68 \\
& Step (-10) & 13 & 1.01 & 0.67 & 6.73 \\
\hline \multirow{2}{*}{ R/F } & Step (+10) & -0.8 & 1.37 & 0.98 & 3.76 \\
& Step (-10) & 21 & 1.06 & 0.63 & 5.85 \\
\hline
\end{tabular}

\subsubsection{Tests under Perturbations on the Feed Flow Rate}

The performance of control structures with perturbations in the feed flow rate is presented only by temporal plots of the ethanol molar fraction in the distillate (see Figure 16). Then, the control performance is evaluated by means of the error criteria and energy consumption.

The control efficacy in handling feed flow perturbations is measured by criteria in Table 9.

The simulation results show that the RR structure fails for changes of $10 \%$ or higher in the feed flow rate. Then, for the sake of comparison, simulations of the three control structures were performed for changes of $8 \%$ (from 0.5842 to 0.6858 ). In general, perturbations in the feed flow cause steady-state errors lower than the deviations produced by perturbations in the feed composition. The RV and $\mathrm{R} / \mathrm{F}$ structures yield smaller bias and IAE than those corresponding to the RR structure, but similar or larger ISE values, owing to the large overshoot arising after step perturbations. Moreover, large $\mathrm{ITAE}_{n s s}$ of the RV structure predicts well the oscillating performance likely due to interactions in the plant. In contrast, the RR structure implies lower reboiler energy consumption than RV and R/F structures, consuming an average energy equivalent to the nominal reboiler heat duty.

Table 9. Performance indicators of control structures—case of feed flux rate perturbations.

\begin{tabular}{clcccccc}
\hline Structure & Perturbation & Bias $\left(\times \mathbf{1 0}^{\mathbf{3}}\right)$ & ISE $\left(\times \mathbf{1 0}^{\mathbf{6}}\right)$ & IAE & ITAE $_{\text {set }}$ & ITAE $_{\text {nss }}$ & Average Heat Duty reboiler $(\mathbf{k W})$ \\
\hline \multirow{2}{*}{$\mathbf{R V}$} & Step (+10) & -0.013 & 1.436 & 0.048 & 0.632 & 0.109 & 2.335 \\
& Step (-10) & 0.010 & 1.227 & 0.042 & 0.517 & 0.136 & 2.135 \\
& Sinusoidal & & 1.163 & 0.049 & 0.739 & & 2.235 \\
\hline \multirow{2}{*}{ RR } & Step (+10) & 0.069 & 12.83 & 0.187 & 3.075 & 0.041 & 1.789 \\
& Step (-10) & -0.082 & 18.28 & 0.224 & 3.663 & 0.033 & 2.669 \\
& Sinusoidal & & 4.175 & 0.098 & 1.650 & & 2.310 \\
\hline \multirow{2}{*}{ R/F } & Step (+10) & -0.029 & 3.396 & 0.088 & 1.318 & 0.044 & 2.407 \\
& Step (-10) & 0.019 & 16.78 & 0.059 & 0.865 & 0.036 & 2.059 \\
& Sinusoidal & & 1.854 & 0.061 & 0.882 & & 2.232 \\
\hline
\end{tabular}



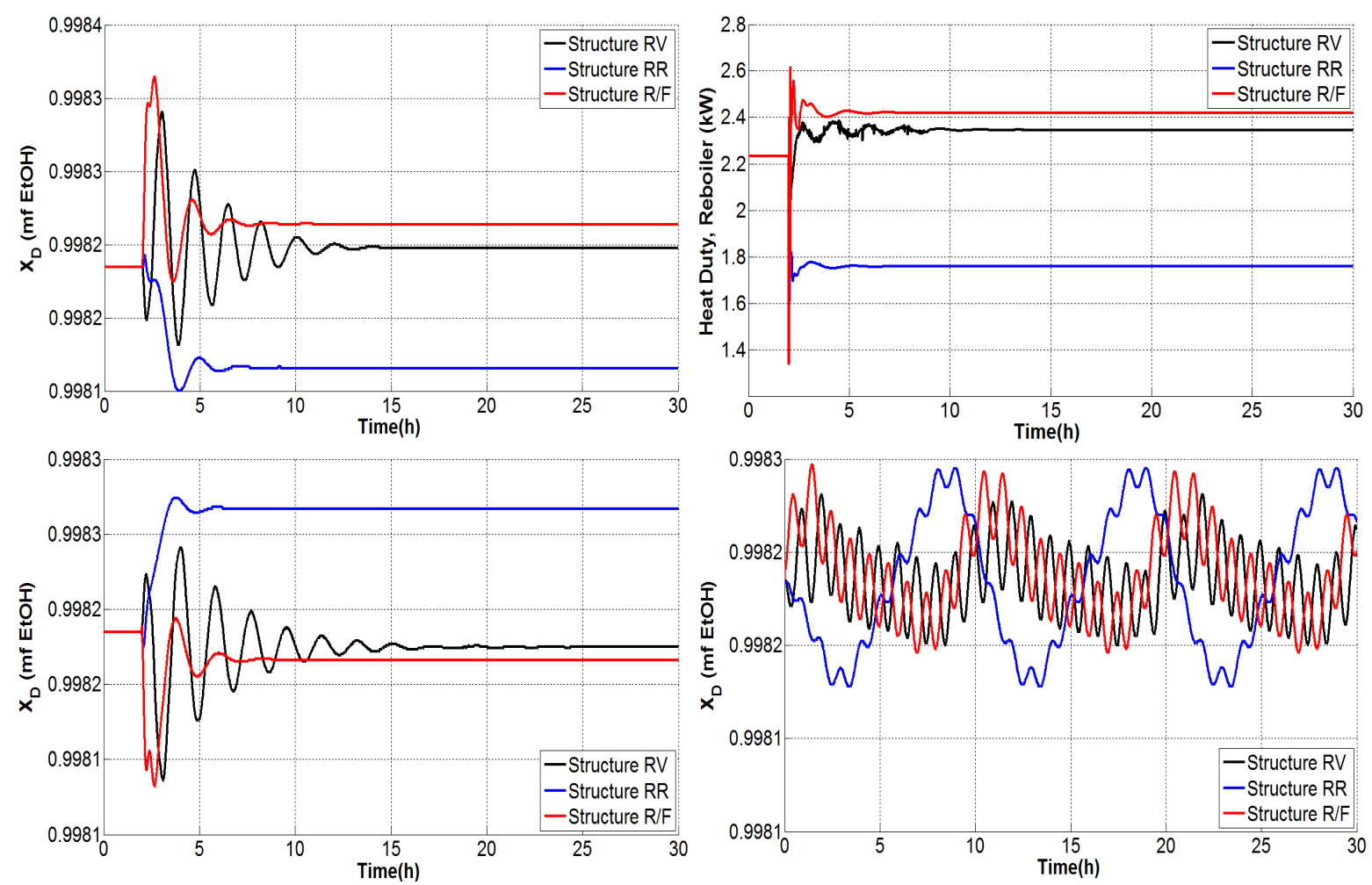

Figure 16. Performance of the structures and reboiler energy consumption under step perturbations of the feed flux rate with amplitude of $8 \%$ and $-8 \%$ with respect to the nominal value, and a continuous fluctuating perturbation.

\subsubsection{Tests under Multiple Perturbations}

Finally, the control structures were tested under simultaneous fluctuating variation of the flow and composition in the feed current. Results are shown in Table 10 and Figure 17. The control performance decayed, causing more than a simple additive effect on the distillate composition, but the purity standards are still largely achieved. The R/F structure improves the transient response of the distillate

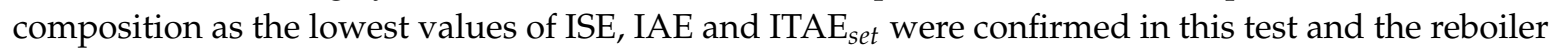
heat consumption fluctuates around the nominal value.
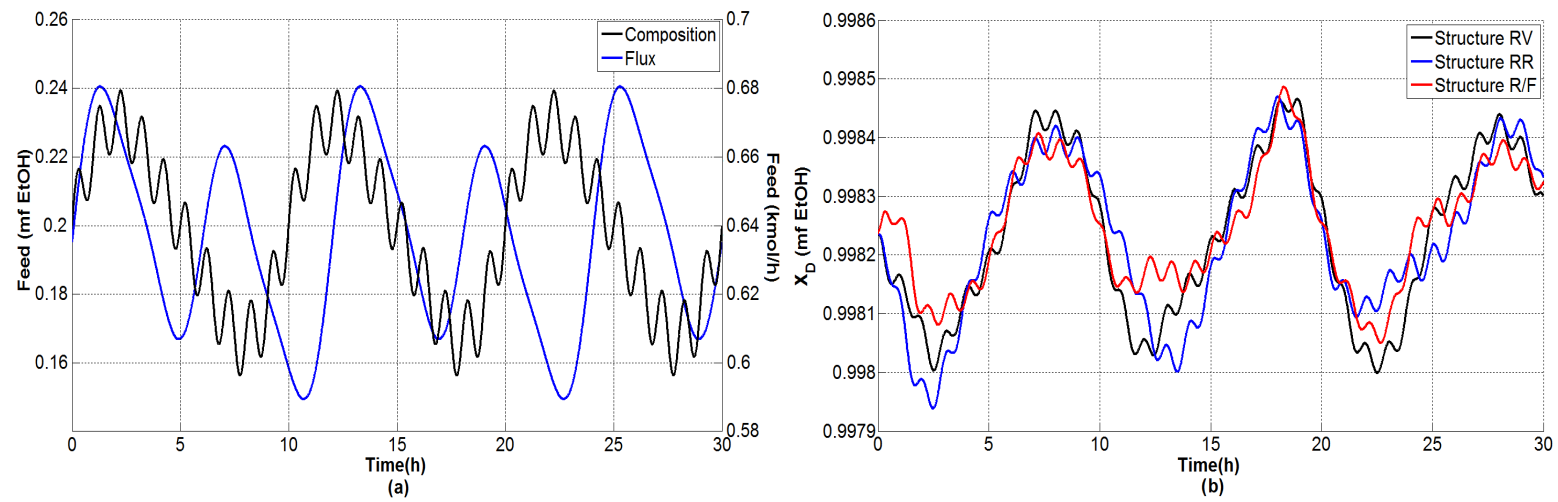

Figure 17. (a) continuous fluctuating perturbation of the feed flux rate and feed molar fraction composition and (b) performance of the structures under oscillating simultaneous perturbations. 
Table 10. Performance indicators of control structures—case of simultaneous feed composition and feed flux rate sinusoidal perturbations.

\begin{tabular}{ccccc}
\hline Structure & ISE $\left(\times \mathbf{1 0}^{\mathbf{5}}\right)$ & IAE & ITAE $_{\text {set }}$ & Average Heat Duty \\
\hline RV & 5.721 & 0.368 & 5.622 & 2.233 \\
RR & 5.560 & 0.353 & 4.957 & 2.208 \\
R/F & 3.326 & 0.268 & 4.165 & 2.226 \\
\hline
\end{tabular}

\subsubsection{General Outcomes}

With respect to the sensor locations, results showed that the temperature control on stage 20 and 22 (for dual temperature control) and stage 20 (for single-end mode control) accomplishes the control targets appropriately. The $\mathrm{CN}$ was estimated to be an intermediate value and offered a previous account of the significance of the dual temperature control problem, which was verified in simulation: the RV structure with two temperature controllers was somewhat easy to handle, but its performance resulted in being poorer than the single-end mode control, and interaction between loops was verified as the product showed oscillating behavior.

Common findings from the tests under perturbations on the composition and flow rate of the feed current, simultaneous or not, are the following:

- The composition of the bottom product was regulated effectively and the molar fraction was kept consistently on the order of $10^{-4}$.

- The dual temperature control was to some extent oscillating, but it was markedly improved with the single-end control mode.

- The flow rate of $\mathrm{CaCl}_{2}$ feed needs indeed undergo fast changes as the inner and external flows change. Because only steady-state studies are reported, it should be useful to verify, in practice, the effect of modifying the salt flow rate with rapid changes, keeping in mind that there exist dissolution difficulties.

- The distillate and bottoms flow rates remain close to the nominal value during the proposed tests; hence, the production rate of absolute ethanol is not affected adversely by disturbances.

- The secondary control loops are correctly achieved and maintain in general a stable operation.

The R/F structure is typically implemented by considering the manipulation of the reboiler duty to regulate the temperature of the selected tray. Nevertheless, we consider the suggestion of Luyben [55] of using instead the distillate flow rate as the manipulated variable. This alternative configuration significantly improves the performance of the control structure, as it led to better performance indicators concerning step or fluctuating perturbations on the feed composition or feed flow rate.

The examined feed flow disturbances are equivalent to changes up to $1.15 \mathrm{~L} / \mathrm{h}$. To give an idea of the influence of these perturbations, we performed a simulation without the temperature control; as a result, the ethanol molar fraction of the product changed from 0.998235 to 0.944329 , even if the rest of the loops remained closed to avoid destabilization of the process and to prevent the operating conditions from varying widely. The tested disturbances affected the purity of the product to such an extent that it was not possible to meet the product quality standards. Similarly, we conducted a simulation without the temperature control, but, instead, we introduced feed composition perturbations that caused changing the product molar fraction from 0.998235 to 0.981895 . The disturbances affected the purity of the product to such an extent that the European and the Brazilian standards were no longer met. On the other hand, the dynamic closed loop simulations demonstrated the effectiveness of the control proposed for the ethanol dehydration plant given that the difference in the product purity compared with the reference value was insignificant for all the cases studied.

Evidently, the purity of the product depends strongly on the execution of the temperature regulation; small errors from the temperature reference produce small deviations of the product 
purity. Then, the main challenge is to implement the designed control structure in a real plant. For a practical implementation, the temperature regulation is quite dependent on the control design, but it is also dictated by the accuracy of the temperature measurement. Errors of the controller output lower than the sensor accuracy do not produce a control signal. However, if the sensor accuracy is high enough, the controller calculus should allow the purity of the product to oscillate within the quality standards. The control structures evaluated previously in the simulation environment produce variations up to $0.35^{\circ} \mathrm{C}$. Then, a compelling question is how to ensure that these small deviations from the temperature reference can be measured to produce a controller action. The International Electrotechnical Commission provided the IEC 60751 International Standard for industrial platinum resistance thermometers and platinum temperature sensors, which specifies four accuracy classes of sensors; among these, the class AA applies for temperatures of $0-150{ }^{\circ} \mathrm{C}$ and allows an accuracy of $\pm 0.28^{\circ} \mathrm{C}$ for temperatures close to $104^{\circ} \mathrm{C}$. In the industry, we certainly encounter a demand for special sensors and, hence, a series of commercial options. For example, the supplier Reotemp (San Diego, CA , USA) offers special resistance temperature detectors (RTD), such as the Adders detectors, conceived for higher precisions and extended range of application. More specifically, a high-performance option is the dual sensor class $\mathrm{Pt} / 385 \mathrm{~A} 5$ that applies for temperatures up to $226.80^{\circ} \mathrm{C}$ and allows an accuracy of $\pm 0.064{ }^{\circ} \mathrm{C}$ for temperatures close to $104{ }^{\circ} \mathrm{C}$. We conclude that the implementation of the designed control is feasible, with the constraint of selecting high accuracy sensors.

Concerning the control effort related to the manipulation of the reboiler heat duty, simulations showed that the feed flow and feed composition perturbations impose eventually maximal increments of the heat duty, between $7 \%$ and $41 \%$ of the nominal value; however, for most of the simulation time, the control signal represents less than $10 \%$ of the nominal heat duty for RV and RR structures and less than $20 \%$ for the R/F structure. These results are consistent with the maximal control efforts allowed in several studies of distillation control, which range typically from $5-40 \%$ of the nominal heat duty measured on the order of MW [28-30,52,55].

\section{Conclusions}

Extractive distillation conceived to exploit the salting-out effect was abandoned after being installed in the industry due to operating difficulties that have now been almost solved; furthermore, the energy viability and the non-polluting nature associated with this technology make it at present a viable alternative for dehydration. ILs and solid salts have common advantages for this application, but attention should be paid to IL selection and IL process modeling by considering their characteristic high viscosity. Likewise, attention should be paid to the selection and handling of solid salts owing to their marked low solubility.

In this work, classic control strategies for two-product distillation have been applied and evaluated for the production of absolute ethanol in a salt extractive distillation column, but some practical aspects were taken into account, e.g., a rough approximation of the column efficiency oversizes the column with respect to the ideal assumption; an additional degree of freedom for feeding the salt completed the control structures, the controllers were tested using continuous fluctuating inputs representing more realistic loads; approximated lags related to variables measurement were considered in the closed loop simulation, which, in practice, alters the dynamics of the systems.

With respect to the steady-state behavior analysis, we conclude that the selection of the total number of stages and the feed location establishes the relationship between the reflux ratio and both product purity and energy consumed by the reboiler. Considering our study case, the low feeding composition of ethanol means a high reflux ratio and low distillate flow rate, which in turn establishes a wide operating region with low variation of the product purity for changes in reflux ratio or reboiler heat duty. In this sense, the performance tests of the three control structures showed good capacity for meeting the product purity under input perturbations; however, we conclude that the R/F single-end configuration is the best control strategy for the designed pilot plant. This finding is made evident by 
their associated lowest integral-errors, best dynamic performance measurements and because energy consumption is consistently kept close to the nominal value.

To extend the control structure to a more realistic case, the following issues need to be addressed: (i) the characterization of the feed current to determine the real composition of the mixture and the ethanol content. The bioethanol from the fermentation of agricultural feedstocks is essentially composed of alcohols, acids, esters and some gases and solids. The processes for eliminating impurities include centrifugation, decantation, and extraction; these processes determine the ethanol content of mixture fed to the dehydration column. (ii) The experimental measurement and the numerical prediction of the VLE considering the real composition of the bioethanol. (iii) The steady state design for a multicomponent distillation. Certainly, higher compositions of the light component in the feed current should lead to different static and dynamic behaviors, the convenient operating region should also be modified, and the best control structure would indeed change. These facts justify the need of studies comparing control structures, and we emphasize the benefits of integrating steady-state and dynamic knowledge into the control design work.

On the other hand, advanced control techniques are used for diverse targets, e.g., disturbance rejection, definition of new references, optimization, energy savings; or to solve different problems, e.g., parametric uncertainty, complex behavior or instability. In distillation processes, the described control objectives are typically looked for in order to address the primary control problems. Nevertheless, these studies certainly need to be built on the basis of a convenient selection of the general control structure since a series of interactions and stability conditions depends on these structures. With this in mind, in the present study, we offer a virtual control platform incorporating a control structure that is an appropriate basis to resolve the various advanced control problems concerning the ethanol dehydration application. Finally, we underline the need to include a rigorous phenomenological modeling of the process and to consider the performance of the secondary control, in order to clearly reproduce interactions between variables and control loops. Moreover, process simulators are useful to emulate real behavior of distillation columns and aid considerably in achieving the control design task.

Acknowledgments: The authors are grateful to Tecnologico Nacional de Mexico (TecNM), particularly to the Instituto Tecnologico de Colima, for their financial support concerning the article processing charge.

Author Contributions: All authors conceived the project design, revised and approved the final manuscript and contributed to the scientific content of the paper. Carlos Alberto Torres Cantero performed the programs and the simulations for aspenONE ${ }^{\circledR}$ (v8, Aspen Technology, Inc., Burlington, MA, USA) and MATLAB 2017a (The MathWorks Inc., Natick, MA, USA). Guadalupe Lopez Lopez and Carlos Alberto Torres Cantero wrote the paper. Guadalupe Lopez Lopez and Victor M. Alvarado performed the analysis and the conclusions. Victor M. Alvarado and Jesse Y. Rumbo Morales supervised and evaluated the design of the controllers and made the graphs. Ricardo F. Escobar Jimenez and Eduardo M. Sanchez Coronado supervised the work.

Conflicts of Interest: The authors declare no conflict of interest.

\section{References}

1. Zabed, H.; Sahu, J.; Boyce, A.; Faruq, G. Fuel ethanol production from lignocellulosic biomass: An overview on feedstocks and technological approaches. Renew. Sustain. Energy Rev. 2016, 66, 751-774.

2. Chuck-Hernández, C.; Pérez-Carrillo, E.; Heredia-Olea, E.; Serna-Saldívar, S. Sorgo como un cultivo multifacético para la producción de bioetanol en México: Tecnologías, avances y áreas de oportunidad. Revista Mexicana de Ingeniería Química 2011, 10, 529-549.

3. Naik, S.; Goud, V.V.; Rout, P.K.; Dalai, A.K. Production of first and second generation biofuels: A comprehensive review. Renew. Sustain. Energy Rev. 2010, 14, 578-597.

4. Madson, P.; Monceaux, D. Fuel ethanol production. In The Alcohol Textbook; Lyons, T., Kelsall, D., Murtagh, J., Eds.; Nottingham University Press: Nottingham, UK, 1995; pp. 257-268.

5. Hettinga, W.; Junginger, H.; Dekker, S.; Hoogwijk, M.; McAloon, A.; Hicks, K. Understanding the reductions in US corn ethanol production costs: An experience curve approach. Energy Policy 2009, 37, 190-203.

6. Tolsma, J.E. Simulation and Analysis of Heteroazeotropic Systems. Ph.D. Thesis, Massachusetts Institute of Technology, Cambridge, MA, USA, 1999. 
7. Cardona, C.A.; Sanchez, O.J. Fuel ethanol production: Process design trends and integration opportunities. Bioresour. Technol. 2007, 98, 2415-2457.

8. Kumar, S.; Singh, N.; Prasad, R. Anhydrous ethanol: A renewable source of energy. Renew. Sustain. Energy Rev. 2010, 14, 1830-1844.

9. Quintero, J.; Montoya, M.; Sanchez, O.; Cardona, C. Evaluation of fuel ethanol dehydration through process simulation. Biotecnología en el Sector Agropecuario y Agroindustrial 2007, 5, 72-83.

10. Zhu, Z.; Ri, Y.; Li, M.; Jia, H.; Wang, Y.; Wang, Y. Extractive distillation for ethanol dehydration using imidazolium-based ionic liquids as solvents. Chem. Eng. Process. 2016, 109, 190-198.

11. Tsanas, C.; Tzani, A.; Papadopoulos, A.; Detsi, A.; Voutsas, E. Ionic liquids as entrainers for the separation of the ethanol/water system. Fluid Phase Equilibria 2014, 379, 148-156.

12. Figueroa, J.; Lunelli, B.H.; Filho, R.M.; Maciel, M.W. Improvements on Anhydrous Ethanol Production by Extractive Distillation using Ionic Liquid as Solvent. Procedia Eng. 2012, 42, 1016-1026.

13. Pereiro, A.; Araújo, J.; Esperança, J.; Marrucho, I.; Rebelo, L. Ionic liquids in separations of azeotropic systems-A review. J. Chem. Thermodyn. 2012, 46, 2-28.

14. Ge, Y.; Zhang, L.; Yuan, X.; Geng, W.; Ji, J. Selection of ionic liquids as entrainers for separation of (water + ethanol). J. Chem. Thermodyn. 2008, 40, 1248-1252.

15. Quijada-Maldonado, E.; Aelmans, T.; Meindersma, G.; de Haan, A. Pilot plant validation of a rate-based extractive distillation model for water-ethanol separation with the ionic liquid [emim][DCA] as solvent. Chem. Eng. J. 2013, 223, 287-297.

16. Ramírez-Corona, N.; Ek, N.; Jiménez-Gutiérrez, A. A method for the design of distillation systems aided by ionic liquids. Chem. Eng. Process. 2015, 87, 1-8.

17. Soares, R.; Pessoa, F.; Mendes, M. Dehydration of ethanol with different salts in a packed distillation column. Process Saf. Environ. Prot. 2015, 93, 147-153.

18. Grundl, G.; Müller, M.; Touraud, D.; Kunz, W. Salting-out and salting-in effects of organic compounds and applications of the salting-out effect of Pentasodium phytate in different extraction processes. J. Mol. Liquids 2017, 236, 368-375.

19. Barba, D.; Brandani, V.; di Giacomo, G. Hyperazeotropic ethanol salted-out by extractive distillation. Theoretical evaluation and experimental check. Chem. Eng. Sci. 1985, 40, 2287-2292.

20. Pinto, R.; Wolf-Maciel, M.; Lintomen, L. Saline extractive distillation process for ethanol purification. Comput. Chem. Eng. 2000, 24, 1689-1694.

21. Ligero, E.; Ravagnani, T. Dehydration of ethanol with salt extractive distillation-A comparative analysis between processes with salt recovery. Chem. Eng. Process. 2003, 42, 543-552.

22. Huang, H.J.; Ramaswamy, S.; Tschirner, U.; Ramarao, B. A review of separation technologies in current and future biorefineries. Sep. Purif. Technol. 2008, 62, 1-21.

23. Nishi, Y. Vapor-liquid equilibrium relations for the system accompanied by hypothetical chemical reaction containing salt. J. Chem. Eng. Jpn. 1975, 8, 187-191.

24. Zhou, R.; Duan, Z. Extractive distillation with salt in solvent. Tsinghua Sci. Technol. 1999, 4, 1477-1479.

25. Vasquez, C.; Ruiz, C.; Arango, D.; Caicedo, R.; Sanchez, M.; Rios, L.; Restrepo, G. Production of anhydrous ethanol by extractive distillation with salt effect. DYNA 2007, 74, 53-59.

26. Llano-Restrepo, M.; Aguilar-Arias, J. Modeling and simulation of saline extractive distillation columns for the production of absolute ethanol. Comput. Chem. Eng. 2003, 27, 527-549.

27. Hashemi, N.; Pazuki, G.; Vossoughi, M.; Hemmati, S.; Saboohi, Y. Application of a New Gibbs Energy Equation to Model a Distillation Tower for Production of Pure Ethanol. Chem. Eng. Technol. 2011, $34,1715-1722$.

28. Luyben, W.L. Effect of Feed Composition on the Selection of Control Structures for High-Purity Binary Distillation. Ind. Eng. Chem. Res. 2005, 44, 7800-7813,

29. Luyben, W.L. Evaluation of criteria for selecting temperature control trays in distillation columns. J. Process Control 2006, 16, 115-134.

30. Luyben, W.L. Distillation Design and Control Using Aspen Simulation; John Wiley Sons: Hoboken, NJ, USA, 2013.

31. Skogestad, S.; Morari, M. Control configuration selection for distillation columns. AIChE J. 1987, 33, 1620-1635.

32. Skogestad, S.; Morari, M. Understanding the dynamic behavior of distillation columns. Ind. Eng. Chem. Res. 1988, 27, 1848-1862, 
33. Skogestad, S.; Morari, M. LV-Control of a high-purity distillation column. Chem. Eng. Sci. 1988, 43, $33-48$.

34. Skogestad, S.; Lundström, P.; Jacobsen, E.W. Selecting the best distillation control configuration. AIChE J. 1990, 36, 753-764.

35. Skogestad, S. Dynamics and Control of Distillation Columns. Chem. Eng. Res. Des. 1997, 75, 539-562.

36. Skogestad, S. Plantwide control: The search for the self-optimizing control structure. J. Process Control 2000, 10, 487-507.

37. Skogestad, S. Self-optimizing control: The missing link between steady-state optimization and control. Comput. Chem. Eng. 2000, 24, 569-575.

38. Skogestad, S. The Dos and Don'ts of Distillation Column Control. Chem. Eng. Res. Des. 2007, 85, 13-23.

39. Waller, K.V.; Finnerman, D.H.; Sandelin, P.M.; Haeggblom, K.E.; Gustafsson, S.E. An experimental comparison of four control structures for two-point control of distillation. Ind. Eng. Chem. Res. 1988, 27, 624-630,

40. Wolff, E.A.; Skogestad, S. Control configuration selection for distillation columns under temperature control. In Proceedings of the 2nd European Control Conference, Groningen, The Netherlands, 28 June-1 July 1993; pp. 637-642.

41. Wolff, E.A.; Skogestad, S. Temperature Cascade Control of Distillation Columns. Ind. Eng. Chem. Res. 1996, 35, 475-484.

42. Khelassi, A.; Bendib, R.; Benhalla, A. Configurations of binary distillation column for optimal control. In Proceedings of 2012 UKACC International Conference on Control, Cardiff, UK, 3-5 September 2012; pp. 793-797.

43. Luyben, W.L. Control of a multiunit heterogeneous azeotropic distillation process. AIChE J. 2006, 52, 623-637.

44. Ramos, W.B.; Figueiredo, M.F.; Brito, R.P. Optimization of Extractive Distillation Process with a Single Column for Anhydrous Ethanol Production. Comput. Aided Chem. Eng. 2014, 33, 1411-1416.

45. Figueiredo, M.F.D.; Brito, K.D.; Ramos, W.B.; Vasconcelos, L.G.S.; Brito, R.P. Effect of Solvent Content on the Separation and the Energy Consumption of Extractive Distillation Columns. Chem. Eng. Commun. 2015, 202, 1191-1199.

46. Ramos, W.; Figueirêdo, M.; Brito, K.; Brito, R. Effect of Solvent Content on Controllability of Extractive Distillation Columns. Comput. Aided Chem. Eng. 2015, 37, 1607-1612.

47. Ramos, W.B.; Figueirêdo, M.F.; Brito, K.D.; Ciannella, S.; Vasconcelos, L.G.S.; Brito, R.P. Effect of Solvent Content and Heat Integration on the Controllability of Extractive Distillation Process for Anhydrous Ethanol Production. Ind. Eng. Chem. Res. 2016, 55, 11315-11328.

48. Ramos, W.; Figueirêdo, M.; Brito, K.; Brito, R. Control of an Extractive Distillation Column with Thermal Integration. Comput. Aided Chem. Eng. 2016, 38, 1329-1334.

49. Luyben, W.L. Comparison of extractive distillation and pressure-swing distillation for acetone/chloroform separation. Comput. Chem. Eng. 2013, 50,1-7.

50. Sander, B.; Fredenslund, A.; Rasmussen, P. Calculation of vapour-liquid equilibria in mixed solvent/salt systems using an extended UNIQUAC equation. Chem. Eng. Sci. 1986, 41, 1171-1183.

51. Pasa, V.M.D. Recomendaciones de Especificaciones Técnicas Para el Etanol y sus Mezclas (E6) y la Infraestructura para su Manejo en México. SENER/ GTZ: Mexico City, Mexico, 2010; p. 100.

52. Luyben, W. Plantwide Dynamic Simulators in Chemical Processing and Control; CRC Press: Boca Raton, FL, USA, 2002.

53. Luyben, W.L. Practical Distillation Control; Springer Science \& Business Media: Berlin, Germany, 2012.

54. Skogestad, S.; Morari, M. Implications of large RGA-elements on control performance. Ind. Eng. Chem. Res. 1987, 26, 2323-2330.

55. Luyben, W.L. Use of Mass or Molar Reflux-to-Feed Ratios In Distillation Single-End Control Structures. Ind. Eng. Chem. Res. 2013, 52, 15883-15895.

(C) 2017 by the authors. Licensee MDPI, Basel, Switzerland. This article is an open access article distributed under the terms and conditions of the Creative Commons Attribution (CC BY) license (http:/ / creativecommons.org/licenses/by/4.0/). 